\title{
Unknown Evils: Revisiting the Psychopathy/Responsibility Debate with Epistemic Injustice
}

Rachel Munro

A thesis submitted to the Faculty of Graduate and Postdoctoral Affairs in partial fulfillment of the requirements for the degree of

Master of Arts

in

Philosophy

Carleton University

Ottawa, Ontario

(C)2019

Rachel Munro 


\section{Abstract}

The callous and seemingly emotionless temperament possessed by individuals with psychopathic traits has caused them to be a source of fascination for psychologists, legal theorists, philosophers and laymen alike. Many authors have offered reconciliation for their harmful actions, contending that without the capacity to appreciate the wrongfulness of their action, individuals with psychopathic traits ought not be held responsible for them. In this thesis, I discuss many of these arguments, examining assertions for a mitigated attribution of both legal and moral responsibility. Additionally, I consider an unexplored aspect within the debate of psychopathy and responsibility: Miranda Fricker's concept of Epistemic Injustice. Using this concept, I contend that the current standard of holding individuals with psychopathic traits criminally responsible reflects pervasive patterns of injustice, and that individuals with psychopathic traits are not deserving of being held fully responsible for their criminal wrongdoings.

\section{Acknowledgments}

I would first like to express my profound gratitude to my thesis supervisor, Dr. Joshua Shepherd of the Philosophy Department at Carleton University, for keeping me positive, focused, and confident in my research. Dr. Shepherd always offered me judicious advice and guidance, whether I needed help in articulating my ideas, or even if I was struggling to find balance between my research and other responsibilities. He consistently allowed this paper to be all my own work and ideas, but steered me in the right the direction whenever he thought I needed it. 
I would also like to thank my committee members, Dr. Gordon Davis and Dr. Julie Blais, for offering their invaluable insight and perspective. My sincere gratitude also goes to Dr. Christine Koggel, for chairing my thesis defence.

Lastly, I would like to thank my parents, for their continued love and encouragement. I could not have completed my education without their financial and emotional support.

Rachel Munro 


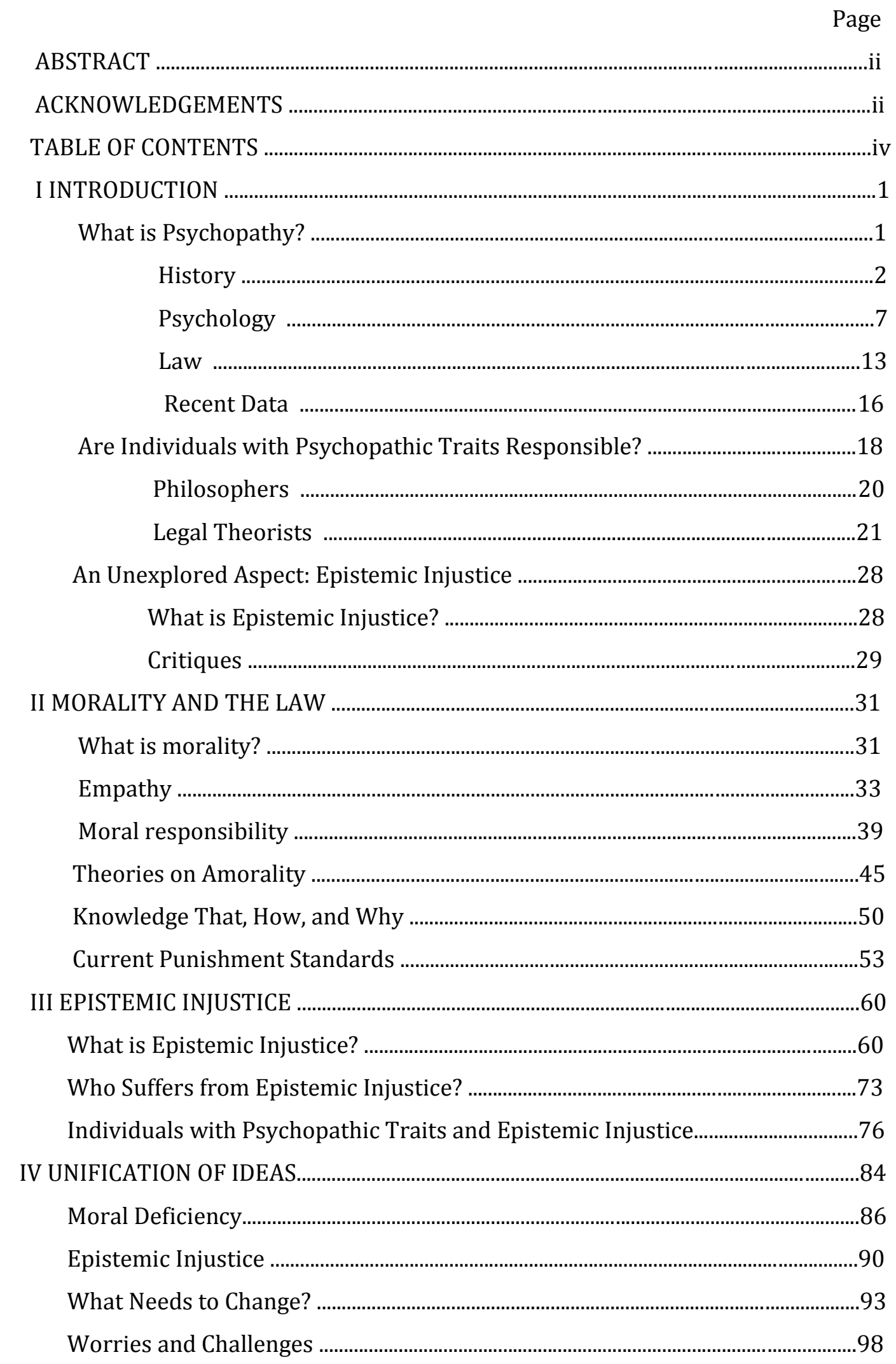




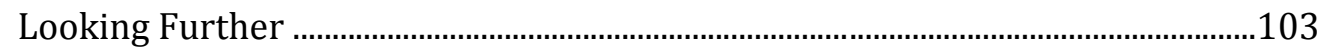

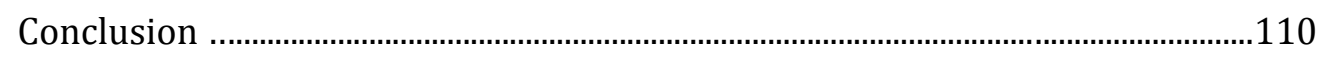

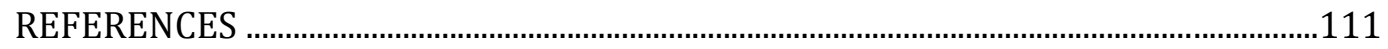




\section{Chapter I}

\section{Introduction}

\section{What is Psychopathy?}

Undoubtedly, most people have encountered the 'psychopathic' character in some sort of popular media. Television and movies make psychopathic serial killers the star of the show, creating excitement around their crimes. People have fallen completely captivated by the cold and cunning monsters that supposedly lurk among us, with their evil identity sometimes remaining completely hidden from public knowledge. Characters such as Hannibal Lector and Norman Bates, or romanticised documentaries about Ted Bundy likely give most people what they believe to be at least a rough idea of what a psychopath is which, usually, consists of being evil or having an uncontrollable urge to kill.

For example, when viewers meet Hannibal Lector from Silence of the Lambs, they meet a brilliant, albeit highly troubled, man that seems to be unable to resist the urge of continuously killing and eating people. Viewers can then jump to the conclusion that because Hannibal is highly intelligent and seems to love to kill people, traits of psychopathy include high intelligence and a senseless urge to kill. It's no surprise to see media sensationalizing psychopathy to seem more appealing to audiences, and admittedly, not much about them needs to be exaggerated. Many people: psychologists, legal theorists, philosophers and laymen alike, are fascinated by the idea of these mysterious, dark characters that walk among us. But, the result causes more harm than the average viewer realizes; depicting the condition in such 
a way creates stereotypes, most of which are highly negative, that follow individuals with psychopathic traits wherever they go.

\subsection{History}

The history of the psychopath could arguably go back as far as human societies. The reason for this is that from an evolutionary standpoint, certain psychopathic behaviours or actions, such as cunning trickery, would have benefitted some in their pursuit to survive. Here, some is the operative term; it is just as important, evolutionarily speaking, that only a small portion of the population exhibited psychopathic behaviours because they would otherwise be ineffectual ${ }^{12}$. Imagine, for example, a hunter-gatherer was trying to collect some fruits and was carrying a large stick for their protection. Imagine now, a second person approaches them with a satchel of fruits and offers to trade some of the fruits for the stick, since they have an excess of fruit. The two individuals could exchange their goods and both be on their way, having gained resources that they both need. However, an example of psychopathic behaviour may be that upon exchanging the fruit for the stick, the second person strikes the first person over the head, takes their fruit back and leaves with both items. This type of behaviour ensured individuals with psychopathic traits both greater resources and less competition in the future. We can also see now why it is important that the gene pool is not oversaturated with

\footnotetext{
${ }^{1}$ Andrea Glenn, Robert Kurzba, and Arian Raine, A. "Evolutionary Theory and Psychopathy" Aggression and Violent Behavior, 16 (2011): 372

2 Thomas Nadelhoffer and Walter Sinnott-Armstrong, "Is Psychopathy a Mental Disease?" in Neuroscience and Legal Responsibility, ed. Nicole A. Vincent (New York: Oxford University Press, 2013), 247
} 
psychopaths; had both persons been prepared to enter the exchange with malicious intent, it's likely that neither would have benefitted ${ }^{3}$. This type of behaviour has been seen to benefit other animals as well. So-called sneaker salmon have been documented sneaking in to fertilize a female's eggs before her chosen partner can, which ensures that his genes will be passed on, rather than the other salmon's ${ }^{4}$. Additionally, psychopathy can be "described as an adaptive competitive strategy that facilitates reproductive success" 5 due to the fact that they tend to engage short term mating tactics and opportunistic/exploitative interpersonal interactions ${ }^{6}$. Individuals with psychopathic traits tend to engage in promiscuous sexual behaviours, such as multiple short-term relationships or marriages, shortterm mating, and having sexual relationships at an earlier age, with multiple partners throughout their life. ${ }^{7}$ Due to these behaviours, it's been found ${ }^{8}$ that individuals with psychopathic traits can sometimes have as many or more children than their counterparts, despite not necessarily staying in a stable relationship.

History has shown people with psychopathic traits from nearly as early as when we begun writing down our history, even if they were not formally titled

\footnotetext{
${ }^{3}$ Robert Hare, developer of the PCL-R told Discover Magazine he believes "it's just as reasonable, and more so in my mind, to interpret psychopathy as a developmental evolutionary thing", Danielle Egan, "Into the Mind of a Psychopath," Discover Magazine, May 4, 2016, http://discovermagazine.com/2016/june/12-psychopath-and-the-hare. ${ }^{4}$ Brent Young, David Conti, and Matthew Dean," Sneaker "Jack" Males Outcompete Dominant "Hooknose" Males under Sperm Competition in Chinook Salmon (Oncorhynchus Tshawytscha), Ecology and Evolution 3 no 15 (2013): 4987-4997

${ }^{5}$ Angela Book, Tabitha Methot-Jones, Julie Blais, Ashley Hosker-Field, Anthony Volk, Beth A. Visser, Nathalie Gauthier, Ronald R. Holden, and Madeleine T. D'Agata “Psychopathic Traits and the CheaterHawk Hypothesis" Journal of Interpersonal Violence, 34 no. 15 (2016): 2

${ }^{6}$ Book et al. "Psychopathic traits and the Cheater-Hawk Hypothesis", 2

${ }^{7}$ Book et al. "Psychopathic traits and the Cheater-Hawk Hypothesis", 2

8 Book et al. "Psychopathic traits and the Cheater-Hawk Hypothesis", 3
} 
"psychopathic" at the time. Athenian general Alcibiades ${ }^{9}$, for example, was described by Hervey Cleckley to be likely a psychopath due to him apparently being well-loved and charming; "he seemed capriciously to court disaster and, perhaps at the behest of some trivial impulse, to go out of his way to bring down defeat upon his own projects" 10 and additionally he was rumoured to possess, "a disregard for accepted rules or commitments and a reckless tendency to seize arbitrarily what may appeal to him at the moment."11

Perhaps the first known to write on our modern conception of psychopathy was one of Aristotle's students, Theophrastus, who wrote of 'the unscrupulous $\operatorname{man}^{12}$ ' in his portrayal of different personality types. He described this type of man as one who will shamelessly lie without remorse to get ahead.

Many philosophers and doctors became interested in the criminal's pathology around late $18^{\text {th }}$ century and early $19^{\text {th }}$ century as arguments and ideas of free will and moral responsibility surfaced..$^{13}$ In the early 1800 s, American physicist Benjamin Rush noted that some of his patients possessed "lucidity of thought combined with innate preternatural moral depravity"14.

In 1809, Philippe Pinel introduced the term manie sans délire (insanity without delirium). Pinel was amongst the first to recognize that madness, or mental

\footnotetext{
${ }^{9}$ Hervey Cleckley The Mask of Sanity; an Attempt to Reinterpret the so-Called Psychopathic Personality (St. Louis: The C.V. Mosby Company, 1941) 341

${ }^{10}$ Cleckley, The Mask of Sanity, 341

11 Cleckley, The Mask of Sanity, 329

12 "The Characters of Theophrastus," Translated by R.C. Jebb accessed August 3, 2019, https://www.eudaemonist.com/biblion/characters/

13 Theodore Millon, Erik Simonsen, and Morten Birket-Smith, "Historical Conceptions of Psychopathy in the United States and Europe." In Psychopathy: Antisocial, Criminal, and Violent Behavior Eds. Theodore Millon, Erik Simonsen, Morten Birket-Smith and Roger D. Davis (New York: The Guilford Press, 1998) 3

14 Millon, Simonsen, and Birket-Smith, "Historical Conceptions of Psychopathy", 4
} 
illness, did not need to signify a deficit in ability to reason. Preceding his work, it was accepted that because madness occurs in the mind, and reasoning occurs in the mind, only a disintegration of reasoning could be considered madness.

In 1824, alienist J.C. Prichard expanded on Pinel's concept, adding the word moralforming the term "moral insanity". 15

It wasn't until much later, in $19^{\text {th }}$ century Germany, that we would see the formation of the words that we know today. In 1891, Julius Ludwig August Koch introduced and popularized the term psychopath from "Die Psychopatische Minderwertigkeiten" (Psychopathic Inferiority), however at this time, psychopathy was used in a much broader, generalized sense to describe individuals who were diagnosed with a plethora of different mental disorders or anti-social behaviours ${ }^{16}$.

The twentieth century is when a greater number of advancements in psychopathy began to take place. Psychiatrist Hervey Cleckley played a large part in developing a contemporary characterization of the psychopath, his work having helped develop most of the antisocial personality side of psychopathy's diagnosis. In 1941, he published the book titled "The Mask of Sanity"17, in which he describes interviews with incarcerated individuals. As the title suggests, Cleckley describes psychopaths as individuals who are perfectly capable of disguising and immersing themselves amongst non-psychopaths. In "The Mask of Sanity", Cleckley also identified a list of sixteen criteria for psychopathy, which are as follows:

\footnotetext{
${ }^{15}$ Millon, Simonsen, and Birket-Smith, "Historical Conceptions of Psychopathy", 8 ${ }^{16}$ Millon, Simonsen, and Birket-Smith, "Historical Conceptions of Psychopathy", 8 ${ }_{17}$ Cleckley, The Mask of Sanity
} 
1. Superficial charm and good intelligence

2. Absence of delusions and other signs of irrational thinking

3. Absence of nervousness or psychoneurotic manifestations

4. Unreliability

5. Untruthfulness and insincerity

6. Lack of remorse and shame

7. Inadequately motivated antisocial behavior

8. Poor judgment and failure to learn by experience

9. Pathologic egocentricity and incapacity for love

10. General poverty in major affective reactions

11. Specific loss of insight

12. Unresponsiveness in general interpersonal relations

13. Fantastic and uninviting behavior with drink and sometimes without

14. Suicide threats rarely carried out

15. Sex life impersonal, trivial, and poorly integrated

16. Failure to follow any life plan

Although Cleckley's list is now somewhat antiquated, Cleckley at least partly influenced Dr. Robert Hare in the creation of the now widely-used PCL-R, as he has borrowed or expanded upon many of Cleckley's factors. 


\subsection{Psychology}

While the whole picture of what makes up individuals with psychopathic traits is yet to be discovered, research continues to emerge that teaches us more and more about them. First and foremost, psychopathy is not technically considered a mental disorder according to the Diagnostic and Statistical Manual of Mental Disorders (DSM). The closest disorder to psychopathy that is included in the DSM is Antisocial Personality Disorder (ASPD). Individuals with psychopathic traits share traits with those who have been diagnosed with ASPD and those with Narcissistic personality disorder; psychopathy's antisocial traits include manipulation, deceitfulness, impulsivity/irresponsibility and risk taking and their narcissistic personality traits include pathological lying, inflated self worth and glibness.

One of the main differences between antisocial personality disorder and psychopathy is the former is highly linked to criminality and criminal behaviour, and meanwhile, psychopathy doesn't necessitate crime-while there are many individuals with psychopathic traits that do commit crimes, there are also many socalled "successful psychopaths" who live crime-free lives, succeeding in careers such as CEOs. Also, anti-social people typically lack the narcissistic personality that individuals with psychopathic traits tend to possess. Further, personality disorders tend to be developed from teenage years to early adulthood 18 (think the "nurture" side of the 'nature vs. nurture' adage), while psychopathy seems more indicative of

\footnotetext{
${ }^{18}$ American Psychiatric Association, Antisocial Personality Disorder DSM-5 301.7 (F60.2) Diagnostic
} and Statistical Manual of Mental Disorders. (Washington, DC, 2013) 
being a condition that an individual is born with. There have been reports of psychopathic individuals who shared some psychopathic traits with relatives. ${ }^{19}$. Because of this distinction, "sociopath" is a term sometimes used to describe an individual who has seemed to "become" a psychopath.

While the DSM mistakenly conflates ASPD and psychopathy, I think that it could be possible to consider psychopathy something more akin to a 'moral disorder'. When stating this, it is to say that individuals with psychopathic traits do not understand morality—or even personhood, for that matter—in the same way that the majority of people do. When an individual with psychopathic traits commits a crime, they know that what they're doing is wrong the same way that a child knows it is wrong to wear a hat inside of church. Knowing that authority has told them to refrain from committing certain acts does not make those rules any less trivial to the individual with psychopathic traits. Like taking off one's hat in church, laws of morality seem baseless to the person with psychopathic traits, because he lacks the fundamental understanding of morality. In other words, individuals with psychopathic traits seem to lack a basic appreciation of moral knowledge that enables most understanding of the weight of their actions.

Psychopathy's diagnostic items, as well as much of the common knowledge we have about it, was largely developed and discovered by Dr. Robert Hare. Due to a lack of a diagnostic tool for psychopathy that was generally agreed upon by professionals, Hare began to develop the psychopathy checklist in 1975, to have the

\footnotetext{
${ }^{19}$ Daniel Blonigen, Brian Hicks, Robert Krueger, Christopher Patrick, and William Iacono "Psychopathic Personality Traits: Heritability and Genetic Overlap with Internalizing and Externalizing Psychopathology." Psychological Medicine, 35 no 5, (2005): 637-48.
} 
final edition published in 2003. Hare developed the Psychopathy Checklist Revised $(\mathrm{PCL}-\mathrm{R})^{20}$, which is a diagnostic tool to help clinical professionals diagnose psychopathy. In 1995, Hare directed NATO's advanced study institute on psychopathic behaviour.

Still, much debate on psychopathy exists: many experts cannot come to a consensus of a clear picture on psychopathy. Further, much of the language used to discuss individuals with psychopathic traits is subjective and broad. Looking at Hare's PCL-R, some generally-accepted traits of psychopathy follow below. Hare developed twenty traits that are categorized into two factors. Factor 1 traits relate to interpersonal and affective deficits while factor 2 traits deal with antisocial behaviours. There are also two traits associated with psychopathy that don't fall into either factor.

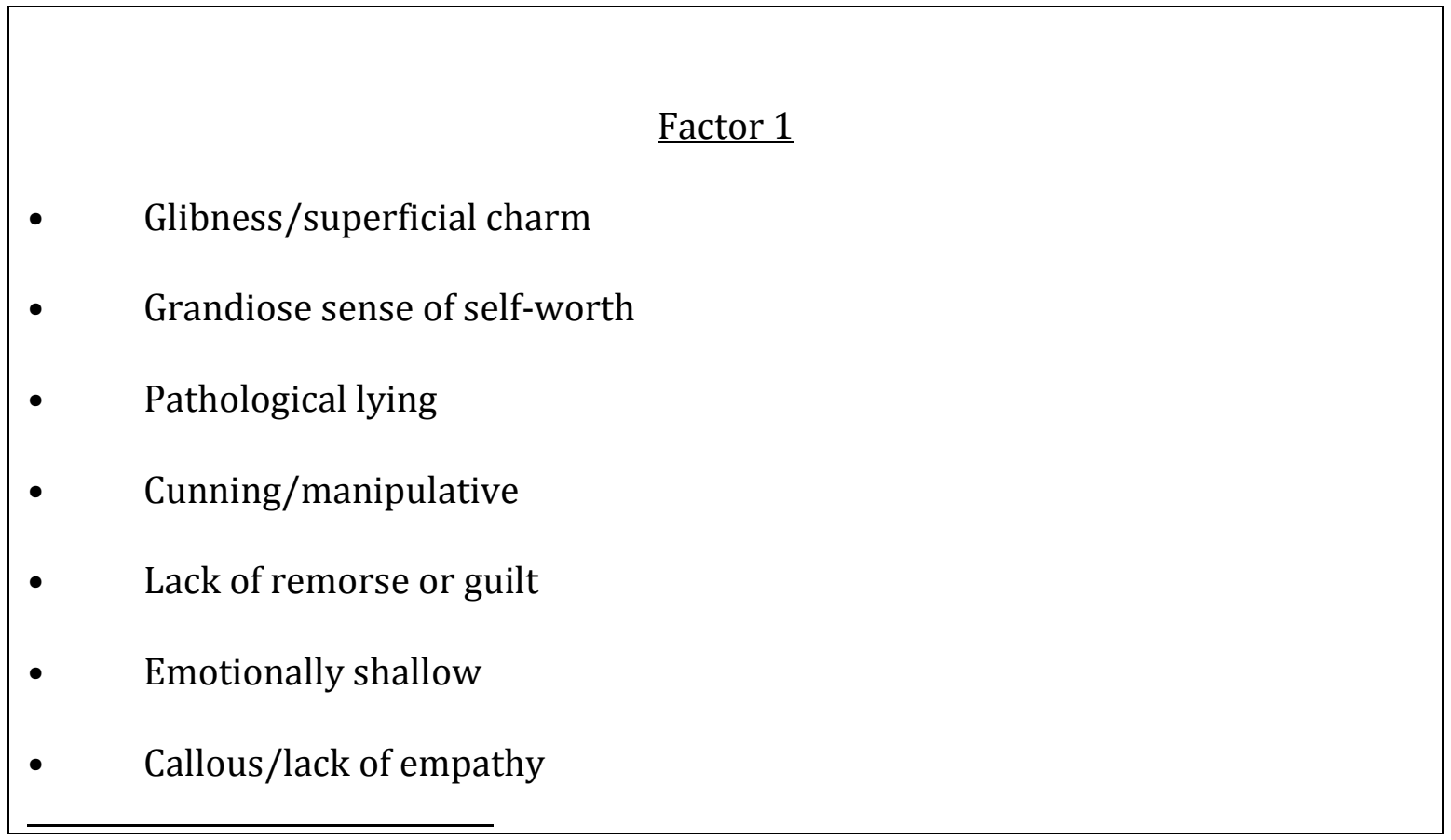

${ }^{20}$ Robert Hare, The Hare Psychopathy Checklist Revised (Hare PCL-R). (Toronto: Multi-Health Systems, Incorporated, 2003) 
- $\quad$ Failure to accept responsibility for own actions

\section{Factor 2}

- $\quad$ Need of stimulation/proneness to boredom

- $\quad$ Parasitic lifestyle

- $\quad$ Lack of realistic long-term goals

- Impulsivity

- $\quad$ Irresponsibility

- $\quad$ Poor behaviour control

- $\quad$ Early behavioural problems

- $\quad$ Juvenile delinquency

- $\quad$ Revocation of conditional release

- $\quad$ Criminal versatility

(Many short-term marital relationships and sexual promiscuity do not fall into either of the factors.)

The PCL-R does not come without its share of criticisms. For example, researchers Cooke and Michie have suggested that based on their findings, Hare's two-factor model "cannot be sustained"21, and suggest that a three-factor or hierarchical model, consisting of Arrogant and Deceitful Interpersonal Style, Deficient Affective Experience, and Impulsive and Irresponsible Behavioural Style,

${ }^{21}$ David Cooke and Christine Michie "Refining the Construct of Psychopathy: Toward a Hierarchical Model." Psychological Assessment, 13 no. 2 (2003): 171 
better suits the disorder. Other authors also share concern with the PCL-R, arguing that the reliability may not always be accurate, specifically in judicial settings. ${ }^{22}$

This could also mean that, potentially, some of the items on the checklist are not needed, or need expanding or are simply missing. However, this shouldn't cause disruption in the arguments I'm putting forth in this thesis, as the central psychopathic traits, shallow affect and impulsivity, do not seem to be highly contested.

Within the checklist, we can unpack the twenty items and go further into what they mean. Impulsivity, irresponsibility and lack of realistic long-term goals, for example, can all work concurrently to create negative behaviours within the individual. An individual with psychopathic traits may momentarily think that it would be a good idea to commit arson. Here, their impulsive and irresponsible behaviour would be to blame. Their unrealistic goal-formation disallows them to fully consider the outcomes of their actions at the current time. Further, their tendency toward pathological lying and failure to accept culpability may lead them to deny the crime even when the evidence is presented before them.

As the PCL-R is a psychiatric tool, clinical professionals can use it as a measure to score an individual with psychopathic traits and evaluate the severity of their condition. Through verbal interview, the clinical professional can score each factor from 0 to 2, where a score of 0 corresponds to exhibiting no instances of the trait, 1 corresponds to moderately exhibiting the trait and 2 corresponds to highly

\footnotetext{
${ }^{22}$ Joakim Sturup, John Edens, Karolina Sörman, Daniel Karlberg, Björn Fredriksson, and Marianne Kristiansson, "Field Reliability of the Psychopathy Checklist-Revised Among Life Sentenced Prisoners in Sweden" Law and Human Behaviour, 38 no 4 (2013): 1-10
} 
exhibiting the trait. Typically, if an individual receives a score of thirty or higher out of a possible forty points, they are deemed psychopathic, although a score of twentyfive is sometimes also used as a cut-off. This should not be interpreted as a score of thirty and twenty-nine will define the difference between psychopathic and nonpsychopathic; the cut-off score should be viewed more akin to template, and determination of whether the individual should be considered psychopathic varies by case.

While the PCL-R is used by many, it is important to keep in mind that it is still a diagnostic tool, and as such is vulnerable to biases, both internal and external. For example, individuals with psychopathic traits are adept at parroting information, so it is not beyond reason that an individual could attempt to mislead the conductor of the interview. There are, however, other ways that can help to determine if an individual is psychopathic, which are more difficult to be falsified by subjects.

First, brain scans can be performed on individuals suspected to be psychopathic. One way to perform this type of test is by displaying sad, fearful or neutral faces on a screen, and to then record the way in which the subject's brain reacts. In the cases of non-psychopathic individuals, increased activations in visual cortical areas of the brain are seen when viewing the sad or fearful faces in comparison to the neutral faces. For psychopathic individuals, the brain activity does not change significantly. ${ }^{23}$

Another way to test for psychopathy is done through physiological testing. Measuring levels of perspiration is one way that this can be done. Researchers found

${ }^{23}$ Elizabeth Shaw, "Psychopathy, Moral Understanding and Criminal Responsibility", European Journal of Current Legal Issues, 22 no 2 (2016): 1-25 
that non-psychopathic individuals perspired far more when shown images of people in distress. Comparatively, psychopathic individuals will perspire far less than their counterparts, if at all ${ }^{24}$. Another physiological test that can help to determine psychopathy is known as startle blink. The startle reflex is a subconscious response to fear. When an object appears to be nearing to hit you in the face, the immediate, uncontrolled reaction is to blink. Researchers were able to measure the speed and well as the time at which the individual closes their eyes to blink (i.e. how quickly and how soon does the person blink). Psychopathic individuals are shown to blink slower and at a later time, suggesting a degree of fearlessness 25 .

\subsection{Law}

Both Canadian and American legal systems have structures to determine whether or not an offender should be considered legally responsible for a crime. The use of mens rea (criminal intent) and actus reus (criminal act) are taken into consideration for determining the individual's culpability for a crime, and these determinations can decide whether an offender is incarcerated or placed into involuntary confinement. For actus reus, any prohibited act that an individual commits, and in any fashion, is taken into consideration. For example, murder by gunshot or by blunt force trauma are equally the same actus reus. With mens rea, it is considered the accompanying intention to commit the act in question. ${ }^{26}$ Further, the law strictly takes all forms of intent into account. So, for example, imagine an

\footnotetext{
${ }^{24}$ Shaw, "Psychopathy, Moral Understanding and Criminal Responsibility", 15

${ }^{25}$ Christopher Patrick, Margaret Bradley, and Peter Lang, "Emotion in the Criminal Psychopath: Startle Reflex Modulation", Journal of Abnormal Psychology, 102 no 1 (1993): 82-92

${ }^{26}$ Stephen J. Morse, "Psychopaths and Criminal Responsibility" Neuroethics 1, no. 3, (2008): 206
} 
emotionally charged, crime of passion where a husband catches his wife cheating and kills her in the heat of the moment. Although he has always very much loved his wife and only for a split second did he intend to kill her, in the eyes of the law, he has a fully formed intent. In other words, it does not make a difference whether the intention was fleeting or enduring, strong or weak; all that matters is that the intention was formed.

A few stipulations exist on what is not considered an act, and as such, when said situations are present, the offender will not be considered responsible for a crime. An example of this could be demonstrated by an individual being coerced, or, in other words, acting under duress. This means that if an individual is being forced or threatened in any way during the time that the crime is committed, it is not considered an intentional act. An example of this situation may be that someone has threatened to kill the individual if they themselves do not commit a crime. Another way which defendants may be considered not responsible is if they can be shown to have acted in self-defence. While murder is a criminal act, killing in self-defence is not, and therefore no actus reus is present.

When both mens rea and actus reus are present, but the offender should nonetheless still be found not responsible for the crime, the offender would either not currently be fit to stand trial or were not in their right mind during the time of the crime. In Canada, instances where an offender is not in their right mind will often find the offender Not Criminally Responsible due to Mental Disease. As Stephen Morse $^{27}$ observes, while the offender has both elements of the crime

\footnotetext{
${ }^{27}$ Morse, "Psychopaths and Criminal Responsibility", 206
} 
present, it is often the case that in the grander scheme, they don't truly understand what they are doing. Morse uses the example of Andrea Yates, who drowned her five children to save them from the wrath of Satan. While she was aware that she was killing her children and that doing so is illegal, she more generally did not seem to understand that drowning her children would not save them from the perceived danger. ${ }^{28}$ When an offender is determined to have been in a state not within their right mind, it refers to the individual not being legally sane, and possesses some type of mental disorder that disables them from appreciating the wrongfulness of a crime.

While versions of the Not Criminally Responsible due to Mental Disease defense (or the United State's insanity defense) have existed as far back as $19^{\text {th }}$ century law, one cannot excuse a crime for a disorder not formally recognized as a mental disease. According to the Criminal Code, in order to be considered not criminally responsible for a crime, one's case must have reached "a verdict that the accused committed the act or made the omission that formed the basis of the offence with which the accused is charged but is not criminally responsible on account of mental disorder"29. Further, the test for determining if an offender has a mental disorder that would excuse them from a crime is also quite rigid. In the United States, the Model Penal Code excludes psychopathy from being considered a mental disease. ${ }^{30}$ Morse observes ${ }^{31}$ that psychopathy is merely considered an

\footnotetext{
${ }^{28}$ Morse, "Psychopaths and Criminal Responsibility", 207

29 The Review Board Systems in Canada: An Overview of Results from the Mentally Disordered Accused Data Collection Study, Canada's Justice System, Department of Justice, Last Modified January 7 2015, https://www.justice.gc.ca/eng/rp-pr/csj-sjc/jsp-sjp/rr06_1/p1.html

30 American Law Institute. "Model Penal Code" (Washington, 1962.)

${ }^{31}$ Morse, "Psychopaths and Criminal Responsibility", 207
} 
aggravating factor in the eyes of the law, and that it cannot be used to excuse a crime in any way.

\subsection{Recent Data}

Although considered somewhat controversial, the Moral/Conventional Distinction Task (MCT) has been a highly cited test to support the argument that individuals with psychopathic traits cannot respond to moral reasons. Developed by Eliot Turiel, the MCT operates under the assumption that from an early age, most people develop the capacity to distinguish between a moral and a conventional transgression. Moral transgressions are infractions or infringements upon moral laws that, for most people, are commonly known to be wrongs in themselves, such as harming another person. A conventional transgression is an infraction or infringement upon the social norms that have been established amongst a community ${ }^{32}$. Chewing with an open mouth or wearing hats indoors are both examples of conventional transgressions; their inherent wrongness largely depends on the demands of the social norms and their relevant temporal, geographic, and ethnographic location. It also examines four dimensions that distinguish moral from conventional: authority independence; involvement of physical welfare, rights or standards of fairness; temporal/geographical universality and seriousness ${ }^{33}$. While

\footnotetext{
32 Kantinka Quintelier and Daniel Fessler, "Confounds in Moral/Conventional Studies”, Philosophical Explorations 18 no 1 (2014): 2

${ }^{33}$ Eyal Aharoni Walter Sinnott-Armstrong, and Kent Kiehl, "Can Psychopathic Offenders Discern Moral Wrongs? A New Look at the Moral/Conventional Distinction", Journal of Abnormal Psychology, 121 no 2 (2012): 485
} 
it doesn't specifically test for psychopathy, as it was originally designed for children, it is designed to test the level of moral comprehension in an individual, which individuals with psychopathic traits are believed to have deficits in. It is referred to in order to attempt to prove that an individual with psychopathic traits does not have access to moral knowledge or reasoning. In his seminal study ${ }^{34}$ on psychopaths and the MCT, R.J.R Blair found that individuals with psychopathic traits struggled with the first dimension, regarding authority independence. In the small, incarcerated sample size that he studied, Blair and his colleagues found that individuals with psychopathic traits largely overclassified conventional transgressions as being authority-independent. So, for example, the individual with psychopathic traits could have been given two scenarios: the first, talking while the teacher is talking and the second, hitting a classmate. Blair would have then asked the individual with psychopathic traits to decide whether these actions were permissible if an authority figure told them it was permissible, or regardless what the authority says, the actions are still wrong in themselves. What Blair discovered was that the individuals with psychopathic traits in his study classified most situations as impermissible regardless of what the authority figure says. This has led many ${ }^{35}$ to speculate on the individual with psychopathic traits' ability with normative reasoning and overall ability to process moral knowledge. The rationale behind those proponents of this hypothesis is that the data from Blair's study displays that individuals with psychopathic traits are unable to distinguish between

\footnotetext{
${ }^{34}$ R.J.R Blair, "A Cognitive Developmental Approach to Morality: Investigating the Psychopath". Cognition, 57 no 1, (1995): 1-29

35 Neil Levy, "Psychopaths and Blame: The Argument from Content" Philosophical Psychology, 27 no. 3 (2014): 351-367; Morse, "Psychopaths and Criminal Responsibility,
} 
a moral and conventional transgression, meaning that they cannot truly appreciate the inherent wrongness behind a moral transgression. It's been hypothesized that this overclassification is from the individual with psychopathic traits' yearning for an early release from prison, and are trying to display that they are reformed.

Blair's study is considered somewhat controversial, however, due to several questionable factors relating to the study itself. Aharoni and Sinnott-Armstrong ${ }^{36}$ note several issues with Blair's study. For example, the sample size was quite small (10 psychopaths and 10 non-psychopaths $)^{37}$ and there have been no successful recreations of the findings. They also took issue with the complete lack of female representation, their use of schoolyard scenarios (i.e. using examples that would be used for children), as well as Blair's use of objective knowledge of general societal beliefs on what's morally permitted.

Aharoni and Sinnott-Armstrong made their own attempt at reimagining a MCT. They included a forced choice that was meant to remove the incentive to overrate the transgressions. ${ }^{38}$ They also argued that the forced choice stipulates a set of correct answers in the normative sense; a failure in finding a correct response is more likely to reflect a moral deficit, compared to the overrated prisoner's responses, which do not necessarily display this. Their results displayed vastly different ones than that of Blair's study, showing that psychopaths rate moral and conventional transgressions quite similarly to non-psychopaths. However, Levy ${ }^{39}$

\footnotetext{
${ }^{36}$ Aharoni and Sinnott-Armstrong, "Can Psychopathic Offenders Discern Moral Wrongs?" 485

37 Blair, "Cognitive Developmental Approach to Morality", 14

38 Blair, "Cognitive Developmental Approach to Morality", 14

39 Levy, "Psychopaths and Blame"
} 
observes that there are flaws with Aharoni and Sinnott-Armstrong's study too. Levy raises the objection that the study only proves knowledge of, or about, rather than knowledge how. Knowledge of something is far easier to obtain than knowledge how. For example, I happen to know about driving race cars, but I definitely do not possess the knowledge how to drive a race car. Similarly, in this case with individuals with psychopathic traits and morality, Levy is arguing that the study is proving that individuals with psychopathic traits possess moral knowledge insofar as they can recognize that there exists a set of rules that most people follow and can point to what is amoral and what is not, but at the same time they do not possess the knowledge how to execute, comply with, recognize, or understand morality. In the same vein, Levy also criticizes the study for the way the questions were laid out (for example: "How would the average person judge this transgression"), meaning that they may not truly reflect how the individual psychopath feels about the transgression, but rather simply how they believe a normal person would answer.

\section{Are Individuals with Psychopathic Traits Responsible?}

The debate about the individual with psychopathic traits' responsibility is one with plentiful data. Below are some views from philosophers and legal scholars on individuals with psychopathic traits' moral and criminal responsibility. While criminal responsibility is not always reflected by moral responsibility, it can be recognized that in an ideal legal system, those who commit serious criminal (and some civil) offences should only be held criminally responsible if we also hold them 
morally responsible. While I think it's very important to be aware with the failures and injustices associated with the legal system, it can still be reasonably agreed upon that in theory criminal and moral responsibility should mirror one another.

\subsection{Philosophers}

The philosophical debate about individuals with psychopathic traits is one with many strong views. On the side that endorses a mitigated attribution of responsibility, lies Neil Levy. Levy proposes that individuals with psychopathic traits should not be held responsible for their actions for a variety of reasons. Perhaps the most compelling is his argument concerning mental time travel (MTT) ${ }^{40}$, which according to Levy, as well as Kennett and Matthews ${ }^{41}$, individuals with psychopathic traits are deficient in, and the content of one's actions. MTT refers to the episodic memory and prospection that most people possess. MTT is the ability to project oneself into the past or present, and to recall events or predict first person events. Importantly, it does not just involve recalling that an event occurred, but also how it occurred ${ }^{42}$, or could occur. The psychopath's deficit in MTT is reflected within their trait of lacking realistic long-term goals. Lacking in episodic memory and introspection may be a source of trouble for individuals with psychopathic traits, because it could correspond to an issue with understanding the

\footnotetext{
40 Thomas Suddendorf, and Michael C. Corballis, (2008). "The Evolution of Foresight: What is Mental Time Travel and is it Unique to Humans?" Behavioral and Brain Sciences, 30, no 3 (2007): 299-313

41 Jeanette Kennett, and Steve Matthews, "Mental time travel, agency and responsibility". In Psychiatry as cognitive neuroscience: Philosophical perspectives ed. Matthew Broome \& Lisa Bortolotti, (Oxford: Oxford University Press, 2009), 327-350

42 Levy, "Psychopaths and Blame", 356
} 
weight and lasting effects involved with a potential crime. Most importantly, Levy argues that due to individuals with psychopathic traits lacking in MTT, their actions do not possess the right kind of moral content. Levy explains, "we can grade the moral content of actions by reference to the reasons for which an agent acts" 43 . So, an action has the highest degree of moral content when an agent acts in response to moral reasons. Similarly, it has lower moral content when the agent is aware of moral reasons that she disregards. Then, an action has the lowest degree of moral content when an agent fails to register any moral reasons at all. "When the psychopath acts, [Levy] claim[s], his/her actions have a low degree of moral content, and therefore justify correspondingly weak reactive attitudes in response." 44 Correlatively, actions that lack or have exceedingly low moral content would make it nearly impossible for the actor to reflect on the situation and experience guilt or remorse. If the agent were failing to register moral reasons at the time, and struggles to reflect on a situation at a later time, it follows that there would be almost no chance of the agent successfully reflecting upon moral reasons that correspond to the situation in question. In an earlier work ${ }^{45}$, Levy defends Blair's aforementioned study in which individuals with psychopathic traits showed difficulty in categorizing moral and conventional transgressions. ${ }^{46}$ According to Levy, this inability to categorize the two types of transgressions displayed how individuals with psychopathic traits are "blind to cues that distinguish moral from

\footnotetext{
${ }^{43}$ Levy, "Psychopaths and Blame", 358

${ }^{44}$ Levy, "Psychopaths and Blame", 358

${ }^{45}$ Neil Levy, "The responsibility of the Psychopath Revisited", Philosophy, Psychiatry \& Psychology, 14 no. 2 (2007): 129-138

${ }^{46}$ Blair, "Cognitive Developmental Approach to Morality", 14
} 
conventional transgressions" 47 . This blindness, he argues, should be a reason why we should not hold individuals with psychopathic traits responsible for their actions. Fine and Kennett ${ }^{48}$ also share Levy's view that Blair's findings from the MCT justifies why individuals with psychopathic traits are deserving a mitigated attribution of responsibility. According to the authors, individuals with psychopathic traits "experience significant dysfunction in domains directly relevant to an assessment of their responsibility" 49 . Fine and Kennett believe that individuals with psychopathic traits fail to pass through stages of moral development at a young age, resulting in lacking the "essential prerequisites of moral life"50. Additionally, they introduce the idea of the somatic marker hypothesis, which posits that bodily states guide emotional decision-making51. Fine and Kennett believe that individuals with psychopathic traits may suffer from somatic marker dysfunction at an early age, which would account for impairment in moral knowledge, their poor performance on the MCT, and why they shouldn't be held fully responsible for their actions.

Vargas and Nichols ${ }^{52}$ critique this particular line of argumentation put forth by Levy. Their contention is that Levy places too much weight on the data discovered by Blair. In a vein similar to Aharoni and Sinnott-Armstrong, Vargas and

\footnotetext{
${ }^{47}$ Levy, "The Responsibility of the Psychopath Revisited", 132

${ }^{48}$ Cordelia Fine and Jeanette Kennett, "Mental impairment, Moral Understanding and Criminal Responsibility: Psychopathy and the Purposes of Punishment", International Journal of Law and Psychiatry, 27 (2004): 425-443

${ }^{49}$ Fine and Kennett, "Mental impairment, Moral Understanding and Criminal Responsibility", 427

50 Fine and Kennett, "Mental impairment, Moral Understanding and Criminal Responsibility", 427

51 Fine and Kennett, "Mental impairment, Moral Understanding and Criminal Responsibility", 430

52 Manuel Vargas and Shaun Nichols, Psychopaths and Moral Knowledge, Philosophy, Psychiatry, \&

Psychology, 14 no. 2 (2007): 157-162
} 
Nichols are dissatisfied with the number of subjects in Blair's study, and suggest that perhaps if the sample size were larger, different results may have been seen.

David Shoemaker ${ }^{53}$ contends that the responsibility of individuals with psychopathic traits depends on which theory of responsibility that we follow. The three types of responsibility that he discusses are attributability-responsibility, answerability-responsibility, and accountability-responsibility. According to attributability-responsibility, an actor is responsible just if their attitudes or actions can be properly attributable to her ${ }^{54}$. According to answerability-responsibility, so long as at least some of the individual's actions or attitudes flow from evaluative commitments that are themselves grounded in reasons, the actor could be subject to demands for justification of the considerations they took to ground said actions or attitudes ${ }^{55}$. Finally, according to accountability-responsibility, to be responsible "is just to be susceptible for being the appropriate target of sanctions (or perhaps rewards, in positive cases) communicating relationship-defining demands, expressed in the moral realm typically via reactive attitudes such as resentment or indignation"56. Shoemaker argues that the only theory of responsibility in which individuals with psychopathic traits could be found not responsible is accountability-responsibility. This is because the key relationship defining demand, to be sensitive to other's future interests and future plans, is lost on individuals with psychopathic traits ${ }^{57}$. While psychopathic people can understand that there are

\footnotetext{
${ }^{49}$ David Shoemaker, "Attributability, Answerability, and Accountability: Toward a Wider Theory of Moral Responsibility" Ethics, 121 no. 3 (2011): 602-632

54 Shoemaker, "Attributability, Answerability and Accountability", 628

55 Shoemaker, "Attributability, Answerability and Accountability", 628

56 Shoemaker, "Attributability, Answerability and Accountability", 628

57 Shoemaker, "Attributability, Answerability and Accountability”, 628
} 
demands expected of them, Shoemaker posits they do not grasp the reason-giving aspect of these demands. And, because of this, they should not be held responsible for their actions according to accountability-responsibility.

A prominent philosopher arguing against the mitigated attribution of responsibility in individuals with psychopathic traits is Heidi Maibom. Maibom argues against absolving individuals with psychopathic traits of their responsibility for several reasons. In her article "Psychopathy: Morally Incapacitated Persons"58, Maibom introduces the objection that the deficiency in moral content that's seen in individuals with psychopathic traits is not sufficient for mitigating responsibility. While she admits that individuals with psychopathic traits suffer from a moral deficiency to some degree, she rejects the idea that their deficiency is sufficient to completely absolve them of their responsibility; she simply doesn't believe that impairment can constitute this. In Maibom's words, individuals with psychopathic traits are more akin to "bad than mad"59. In other words, the motivations behind the individual with psychopathic traits' actions share no significant similarities to the motivations behind the actions of someone who's mentally ill. She believes that rather than deriving from an uncontrollable illness, the individual with psychopathic traits' motivations derive from the individual's flawed character. She also observes that individuals with psychopathic traits are not typically given any special considerations as they pass the test of mens rea and actus reus. She raises the concern that because they fall within every criteria stipulated by the legal system,

\footnotetext{
${ }^{58}$ Heidi Maibom, “Psychopathy: Morally Incapacitated Persons," Eds. Thomas Schramme \& Steven Edwards Handbook of the Philosophy of Medicine (Dordrecht: Springer.2017): 1109-1129

${ }^{59}$ Heidi Maibom, "The Bad, The Mad and The Psychopath", Neuroethics, 1 no 3 (2008): 168
} 
making special considerations could potentially contravene the entire point of the legal system in which we punish those that commit illegal actions ${ }^{60}$. Advocates of this objection may also claim that failing to recognize that an individual has committed an illegal action won't teach that individual anything, and those that break the law require a punishment.

Also arguing against mitigated attribution of responsibility for individuals with psychopathic traits is Matthew Talbert. ${ }^{61}$ Using a Strawsonian definition of responsibility, that "the responses that characterize moral blame are essentially reactions to the quality of others' wills towards us, as manifested in their behaviour: to their good or ill will or indifference or lack of concern ${ }^{62}$, while also maintaining that sensitivity to moral reasons is not necessary for moral blameworthiness, Talbert contends that individuals with psychopathic traits ought to be held responsible for their actions. Talbert argues that it is a mistake to assume that just because individuals with psychopathic traits are unable to recognize moral reasons, they therefore see no reasons at all. Just because individuals with psychopathic traits do not possess the conceptual tools to judge or understand the permissibility of their actions, there is no reason to believe that they cannot judge the effect of their actions. Individuals with psychopathic traits are in fact rational, according to Talbert, because their actions do not reflect them acting in irrational ways, such as how a kleptomaniac acts when they steal something.

\footnotetext{
60 Maibom, "The Mad, the Bad and the Psychopath", 168

${ }^{61}$ Matthew Talbert, "Blame and Responsiveness to Moral Reasons: Are Psychopaths Blameworthy?" Pacific Philosophic Quarterly, 89 no. 4 (2008): 516-535

62 Talbert, "Blame and Responsiveness to Moral Reasons", 518
} 


\subsection{Legal Theorists}

Legal theorists also possess strong views on psychopathy and responsibility. Stephen Morse advances what he calls a "specific theory concerning psychopath's rational capacities"63. According to Morse, individuals with psychopathic traits have particularized deficits in rationality when concern and respect for others comes into question. The best reasons that people have for not harming one another, he argues, is the capacity to appreciate and understand the pain they could inflict upon their potential victim. If this capacity to empathize is not present, the only deterrent keeping the individual with psychopathic traits from acting is the potential to be incarcerated. Fear of incarceration, however, is also not often present because psychopathic fearlessness, lack of realistic long-term goals and deficit in MTT. So, Morse argues, the individual with psychopathic traits is not responsive to moral reasons, even if they can be responsive to other reasons. Because of this, individuals with psychopathic traits lack the capacity for moral rationality, which is the crux to why Morse believes they should not be held responsible; "they have no access to the most rational reasons to behave well." 64 While Maibom provided a strong argument as to why individuals with psychopathic traits are not mentally ill, Morse's solution is simple; rather than considering individuals with psychopathic traits as mentally ill, the criterion for criminal insanity should be widened so that the scope can reach to individuals with psychopathic traits.

${ }^{63}$ Morse, "Psychopaths and Criminal Responsibility", 208

${ }^{64}$ Morse, "Psychopaths and Criminal Responsibility", 208 
Legal theorist Elizabeth Shaw also advances arguments as to why individuals with psychopathic traits should not be held responsible for their actions. Shaw relies on how individuals with psychopathic traits perform on Turiel's MCT for evidence that they lack conceptual moral knowledge ${ }^{65}$. As a legal theorist, she places high importance on an offender having a strong grasp of the difference between a crime being mala in se (wrong in itself) and mala prohibitia (wrong because it's illegal) ${ }^{66}$. According to Shaw, legal testing for psychopathy could consist primarily of psychiatric testing, physiological testing and brain scans.

Psychiatric testing intuitively seems to be the most natural first step in determining psychopathy in a defendant. Not only would the tests be administered by those qualified to conduct interviews using the PCL-R, they would also be qualified to conduct MCT testing. Effectively, they could determine how high (if at all) the individual might score using the PCL-R and also determine whether or not the individual possesses any understanding of moral content within their own actions and other actions alike.

To further establish proof of psychopathy, brain scans and physiological testing could be administered to the individual. Shaw explains that there are different ways to react to moral content, both inside the brain and outside the brain, depending on whether or not an individual is psychopathic.

Both physiological testing and brain scans are even stronger proofs than psychiatric interviews. Critics object that individuals with psychopathic traits can be deceitful during their interviews or will parrot information to tell the interviewer

65 Shaw, "Psychopathy, Moral Understanding and Criminal Responsibility", 7

${ }^{66}$ Shaw, "Psychopathy, Moral Understanding and Criminal Responsibility", 8 
what they think wants to be heard. While they are more difficult to falsify, it is important to note that even brain scans have their limits; currently polygraph tests are not considered admissible in court specifically because they can be falsified.

\section{An Unexplored Aspect: Epistemic Injustice}

\subsection{What is Epistemic Injustice?}

In "Epistemic Injustice: Power and the Ethics of Knowing", Miranda Fricker introduces the term 'epistemic injustice', which she describes as "a wrong done to someone specifically in their capacity as a knower". Kryastous and Sanati explain Fricker's concept well: "the basic idea is that a speaker suffers epistemic injustice if the prejudice on the hearer's part causes him to 'make an unduly deflated judgement of the speaker's credibility, perhaps missing out on knowledge as a result'”, ${ }^{67}$ That is, a speaker can suffer an injustice if the hearer holds a prejudice that causes weakened receptiveness toward the speaker. According to Fricker, there are two types of epistemic injustice that an individual can suffer: testimonial injustice and hermeneutical injustice.

Testimonial injustice "occurs when prejudice causes the hearer to give a deflated level of credibility to the speaker's word." 68 Hermeneutical Injustice occurs when concepts are poorly understood, or perhaps completely unknown by society and thus, the lack of understanding bars the individual from the proper resources or

\footnotetext{
${ }^{67}$ Michalis Kyratsous and Abdi Sanati, "Epistemic injustice and responsibility in borderline personality disorder", Journal of Evaluation in Clinical Practice, 23 (2017): 974

${ }_{68}$ Miranda Fricker, Epistemic Injustice: Power and the Ethics of Knowing Oxford: Oxford University Press, 2007), 20
} 
navigation that they might require. An example of this could be a woman reporting sexual assault in a society that has yet to recognize justice for crimes of a sexual nature.

\subsection{Critiques}

Recently, more authors have expanded upon and offered developments to Fricker's concept. For example, Rebecca Mason ${ }^{69}$ suggests that two kinds of ignorance arise from hermeneutical injustice. First, marginalized groups lack the hermeneutical resources to fully understand their own oppression. Second, dominant social groups may remain ignorant of the oppression faced by marginalized groups. ${ }^{70}$

Polhaus Jr. ${ }^{71}$ recognizes a flaw in Fricker's concept. According to Fricker, once the dominant group has recognized the injustice and society has become aware, a hermeneutical resource has become available and knowledge has spread widely enough, the injustice will cease. Polhaus Jr. raises an important question: what about when the dominant social group is wilfully ignorant or chooses not to acknowledge the injustice? ${ }^{72}$ This is an important question because this very situation occurs quite frequently. For example, as Rachel McKinnon ${ }^{73}$ observes, "many men - and some women - actively deny that rape culture exists, and they

${ }^{69}$ Rebecca Mason 'Two kinds of unknowing.' Hypatia 26 no. 2 (2011): 294-307

70 Mason, "Two Kinds of Unknowing”, 295

${ }^{71}$ Gaile Polhaus Jr., "Relational Knowing and Epistemic Injustice: Toward a Theory of Wilful Hermeneutical Ignorance." Hypatia 27 no 4 (2012): 715-735

72 Polhaus Jr., "Relational Knowing and Epistemic Injustice", 717

${ }^{73}$ Rachel McKinnon, "Epistemic Injustice”, The Philosophy Compass, 11 no 8 (2016): 437-446 
thus fail to see the way that it operates, perpetuating women's (and some men's) oppression."74

Dotson ${ }^{75}$ has also offered suggestions on improvement to Fricker's concept. She introduces two new terms: testimonial quieting and testimonial smothering. Testimonial quieting arises from the wilful ignorance of the hearer. If the audience possesses an identity prejudice toward the speaker, and, as a result, they do not properly regard the speaker as a knower, then the speaker is experiencing testimonial quieting. In this case, the hearer does not regard the speaker as a source of knowledge at all (as opposed to one simply with low credibility) — the speaker is completely ignored. Testimonial smothering occurs if the speaker can recognize that the audience is unreceptive to them due to the identity prejudice and chooses to not speak, knowing that they wouldn't be truly heard. ${ }^{76}$

\footnotetext{
${ }^{74}$ McKinnon, "Epistemic Injustice", 442

${ }^{75}$ Kristie Dotson, "Tracking epistemic violence, tracking patterns of silencing." Hypatia 26 no 2 (2011): 236-257

${ }^{76}$ McKinnon, "Epistemic Injustice", 442
} 


\section{Chapter II}

\section{Morality and the Law}

While discussing psychopathy and responsibility, it is crucial to discuss just what is meant when discussing morals, morality and empathy, because there are so many different things one could be referencing when using these terms. To simply say that individuals with psychopathic traits lack morality is not sufficient to fully explicate the nature of psychopathy. For example, when we use the word 'morality', we could be referencing anything from moral reasons, to moral knowledge, moral understanding, moral theories or moral codes. In this Chapter, I will discuss various conceptions of morals, moral responsibility and empathy. Additionally, I will discuss current punishment standards within the United States and Canada.

\section{What is Morality?}

Pinpointing precisely what is meant by morals or morality has proven to be decidedly difficult, as it can refer to a plethora of concepts and ideas. Equally trying is the task of proving the opposite; what is amorality, and what does it mean to be amoral? Generally, we can recognize two different definitions of morality, and define them like so:

1. Descriptively to refer to certain codes of conduct put forward by a society or a group (such as a religion), or accepted by an individual for her own behaviour, or 
2. Normatively to refer to a code of conduct that, given specified conditions, would be put forward by all rational persons. ${ }^{77}$

The second, normative, definition resonates most closely to what we think of when we claim that individuals with psychopathic traits are lacking morality because it seems that when individuals with psychopathic traits commit crimes or act coldly toward others they are blatantly ignoring a code of conduct that comes naturally to most. Whether the person with psychopathic traits is or is not acting in disregard to a code of conduct is vitally important within the discussion of their responsibility for their actions. The operative term in this definition, then, is that all rational persons tend to put it forward. Bernard and Joshua Gert note,

"that a person meets these conditions is typically expressed by saying that the person counts as a moral agent. However, merely showing that any moral agent would accept a certain code is not enough to show that the code is the moral code. It might well be that all moral agents would also accept a code of prudence or rationality, but this would not by itself show that prudence was part of morality."78

Morality as a code of conduct could also more broadly be described as an interpersonal sensitivity, specifically within this discussion of psychopathy. Where most rational persons tend toward feelings of empathy, guilt, sorrow or remorse

\footnotetext{
77 Bernard Gert and Joshua Gert, "The Definition of Morality", The Stanford Encyclopedia of Philosophy (Fall 2017 Edition), Edward N. Zalta (ed.), https://plato.stanford.edu/archives/fall2017/entries/morality-definition/ 78 Gert and Gert "The Definition of Morality"
} 
either if they've harmed someone or they witness someone being harmed, the individual with psychopathic traits is deficient or blunted in these emotions.

Under normal circumstances, most people recognize that it is not permissible to kill another human being. But, what if we witnessed someone attacking a child? For most, it would feel as though it's their duty to try to protect the child. In that case, in order subdue the attacker, they may have to use force, which could harm or even kill the attacker. In this case, it's difficult to say whether killing the attacker was morally right or morally wrong. Some would argue for the former, while some would argue for the latter. But, we can ask the person that stepped in, even though you saved the child's life, do you still feel bad that you took another person's life? There's a high probability that if the individual stepping in has never taken another person's life before (or even if they have) they would remain traumatized for some time for what they had done. So, descriptively, whether or not the act was moral remains debateable. But, normatively, the individual can display or show that they possess morality from their interpersonal sensitivities.

\section{Empathy}

Empathy can be tied into morality by returning to our broad, normative definition of morality. In order to follow a code of conduct that keeps interpersonal sensitivities in mind, it is imperative that individuals are able to empathize with one another. Often, empathy can be confounded with sympathy, or at the very least, people are not entirely sure how to distinctly separate the two terms. Sympathy can 
most accurately be described as "feelings of pity and sorrow for someone else's misfortune"79, while empathy can best be explained as "the ability to understand and share the feelings of another". 80

In other words, while sympathizing refers to simply the acknowledgment of an individual's pain and/or hardships, empathizing with an individual's pain or hardship means you've been in their very situation and know just how they feel, or can at least imagine it. Empathy is such a powerful emotion because a person's compassion means more to us when that person understands how we feel, making that connection with us based on a shared hardship.

Empathy, or lack thereof, is the main trait that is pointed to in individuals with psychopathic traits for a lack of morality. In order for someone to act within the code of conduct, or have access to interpersonal sensitivities, one must be able to access the reasons why we should follow this code of conduct. Without the capacity to empathize with others, one lacks that access to reasons why we shouldn't harm one another-for example, we can envision and imagine that pain, and would not want that done to us, so we should likewise not do it to others. Our capacity to empathize is what drives the force behind our moral behaviours; we don't mistreat others because we wouldn't want to be treated that way either. It's a mistake to say that we refrain from trespassing upon others simply because "it's wrong" - the only way for us to understand the inherent wrongness of harming others is our ability to reflect and relate using our empathy.

\footnotetext{
79 "Sympathy," Definition of Sympathy in English, Lexico, accessed August 3, 2019, https://www.lexico.com/en/definition/sympathy.

80 "Empathy," Definition of Empathy in English, Lexico, accessed August 3, 2019, https://www.lexico.com/en/definition/empathy.
} 
Being an empathetic person seems to be fundamentally tied with being a remorseful person ${ }^{81}$, particularly within the discussion of individuals with psychopathic traits. Feeling remorse or guilt for our actions entails a semblance of empathy, or at least sympathy. To feel sorry for doing something to someone-as opposed to feeling sorry that you got caught, or feeling embarrassed for yourselfwill then require one to have the capacity to empathize with the pain that they have caused to the recipient of their harm. But what about those who do not empathize with their victims? Does this mean that it will be nearly impossible for them to feel remorse as a result? This seems to be the position that common view has taken. Empathy plays a huge role not only in how we view people's characters, but also in our legal system. An offender's demeanour can play a highly important role in their criminal future. If the offender can convincingly prove to a judge that they are regretful for their actions ${ }^{82}$, it's often seen that this will be taken into consideration for sentencing. However, I'm not convinced that sentencing is the right time to examine an offender's level of remorse. Further, the practice's attempt at dividing those who are remorseful for their crimes from those who aren't is doing nothing more than placing a target on the backs of offenders with diminished moral capacities. This brings up questions of authenticity in statements, specifically

\footnotetext{
${ }^{81}$ Almost any author will use "lack of empathy/remorse" when describing psychopathic traits where even the PCL-R equate the two; see these examples:

Heidi Maibom, "Moral Unreason: The Case of Psychopathy", Mind and Language, 20 no 2 (2005): 237-257, John Edens, Karen Davis, Krissie Smith and Laura Guy, "No Sympathy for the Devil: Attributing Psychopathic Traits to Capital Murderers Also Predicts Support for Executing Them", Personality Disorders: Theory, Research, and Treatment, 1 no 2 (2005): 175-181,

${ }^{82}$ Rocksheng Zhong, Madelon Baranoski, Neal Feigenson, Larry Davidson, Alec Buchanan and Howard V. Zonana, "So You're Sorry? The Role of Remorse in Criminal Law", Journal of the American Academy of Psychiatry and the Law, 42, no. 1, (March 2014), 39-48
} 
surrounding those who express deep remorse following heinous crimes. It also remains unclear why a system that supports retribution places such importance on the genuine feeling of remorse. But this aside, the important question to ask is this: should an individual who displays stronger emotions at trial, but committed an equal crime in every aspect to his psychopathic counterpart truly be punished less for their crime? While rehabilitative legal systems are proven $^{83}$ to be beneficial in lowering rates of reoffending, offering an offender the chance to barter for their lives hardly seems like the time or place to display true feelings of empathy and remorse for the lives and individuals they may have harmed. And so, perhaps nearly none of the offenders who have been offered a 'final chance' to display their empathy are truly showing it, and only the best actors are given reduced sentences.

As with any other controversial topic, empathy does not come without its share of detractors. Notably, Paul Bloom ${ }^{84}$ argues against empathy, contending that it risks biases, racism and parochialism ${ }^{85}$. Bloom's assertion is that because empathy relates to imagining one's pain, in a plethora of events people's attention tends to shift to that which is closer or more visible to them, and not necessarily what is fair, or what is causing the most harm or suffering. Bloom uses several examples to illustrate this phenomenon.

\footnotetext{
${ }^{83}$ Many studies, books, textbooks, papers have shown that rehabilitation reduces recidivism in prisoners. For example: Danielle S. Nagin, Alex R. Piquero, Elizabeth S. Scott, and Laurence Steinberg, "Public Preferences for Rehabilitation versus Incarceration of Juvenile Offenders: Evidence from a Contingent Valuation Survey", Criminology and Public Policy, 5 no. 4, (2006): 627-651 Allan I. Abrams and Larry M. Siegel, "The Transcendental Meditation Program and Rehabilitation At Folsom State Prison: A Cross-Validation Study" Correctional Psychologist, 5 no. 1, (March 1978): 3-20 Earl O. Strimple "A History of Prison Inmate-Animal Interaction Programs." American Behavioral Scientist 47, no. 1 (September 2003): 70-78.

84 Paul Bloom “Empathy and its Discontents" Trends in Cognitive Science 21, no. 1 (2017): 24-31

85 Paul Bloom. "Empathy and its Discontents", 25
} 
First he describes an experiment done where subjects were told about a 10year-old girl, named Sheri Summers, who was terminally ill and low on the waiting list for a treatment. Subjects were then given the option to move Sheri to the top of the list, but this would entail denying another sick child the treatment. Most of the subjects replied that they would not move Sheri up, unless they were first asked to feel what Sheri felt, which lead to most subjects moving Sheri to the top ${ }^{86}$.

In one other example, Bloom describes how during the genocide in Darfur, the attention of many Americans was focused on the disappearance of Natalee Holloway, an 18-year-old girl who went missing in Aruba ${ }^{87}$.

In both examples, Bloom argues that we can see how people opt for emotions rather than fairness or the greater good. In the first example, once people were told to relate the young girl, they opted for an unfair decision; the other, nameless, child who was presumably equally as sick as young Sheri, could now potentially die or at least suffer longer, even though it was their turn to receive the treatment. Bloom argues that this shows how empathy causes us to act unjustly. In the second example, he contends that it shows how empathy causes us to focus on the more immediate and related cases, even when there are greater atrocities happening. The suffering of an "attractive, white American and her family [is] more salient to white Americans than the suffering of many thousands of faraway strangers" 88

Bloom's implication is that empathy is not needed in order to act in accordance to moral reasons, and in fact, it actually causes more harm than good. He

86 Bloom, "Empathy and its Discontents", 25

${ }^{87}$ Bloom, "Empathy and its Discontents", 26

${ }^{88}$ Bloom, "Empathy and its Discontents", 26 
argues that instead, we should act with compassion, a precursor to empathy, so that we can make better-informed decisions on where to place our empathy. If we act with compassion rather than empathy, then we can act with moral reasoning in mind.

It may seem from Bloom's argument that if we can act in accordance to moral reasons without empathy—and that it's actually not even required to act in accordance with moral reasons, then individuals with psychopathic traits should be able to as well, and therefore we ought to fully blame them for their actions. However, I don't think that this view holds much weight. In order for this to be true, individuals with psychopathic traits would first need to be able to act compassionately, which they are equally unable to do. Even though we can separate the emotions, Bloom himself admits that compassion is the precursor to empathy, and as such both compassion and empathy are clearly related. Moreover, Bloom's picture of empathy is important when looking at a macro view of exchanges, but it doesn't tell us much about a micro view. Specifically, Bloom's view would not necessarily be very helpful for individuals with psychopathic traits (or anyone) to deliberate over reasons to avoid causing harm to another person. And, even if it could be helpful for us to exercise compassion in these sorts of deliberations, the facts remains that individuals with psychopathic traits would not have access to this emotion. 


\section{Moral Responsibility}

What is meant in discussions of moral responsibility? What makes an individual morally responsible, and perhaps even more interesting, what excludes an individual from being morally responsible? When an agent performs, or fails to perform an action that we deem to be morally significant, we will sometimes think that some kind of response is warranted ${ }^{89}$. Essentially, "to be morally responsible for something, say an action, is to be worthy of a particular kind of reaction-praise, blame, or something akin to these-for having performed it." 90

Several authors have offered views on the concept of responsibility, but broadly, two main concepts of moral responsibility have emerged: a merit-based view, and a compatibilist view. Merit-based views hold that praise or blame are appropriate reactions if and only if the agent is deserving of such reactions. Compatibilist views hold that praise or blame are appropriate if and only if these reactions will lead to a desirable change in the actors behaviour or actions. ${ }^{91}$

P.F Strawson ${ }^{92}$ has offered one of the most influential pictures of moral responsibility, in which he holds that an individual's responsibility rests upon theoretical judgements of them being responsible ${ }^{93}$.

Many authors have also built upon Strawson's work. For example, some philosophers hold that an agent is only responsible if it is appropriate for us to hold

89 Andrew Eshleman "Moral Responsibility", The Stanford Encyclopedia of Philosophy (Winter 2016 Edition), Edward N. Zalta (ed.), https://plato.stanford.edu/archives/win2016/entries/moral-responsibility 90 Eshleman "Moral Responsibility"

91 Eshleman "Moral Responsibility"

92 Peter F. Strawson. "Freedom and Resentment," Proceedings of the British Academy, 48 (1962): 1-25 Reprinted in Fischer and Ravizza, 1993

93 Eshleman "Moral Responsibility" 
them accountable for their actions via reactive attitudes (such as anger, resentment, gratitude or joy). ${ }^{94}$ According to this view, which shares a main view with Strawson, our ascription of responsibility is fundamentally social, because our reactive attitude is shared with other members of the moral community ${ }^{95}$.

Another set of views, called "ledger views" hold that agents are responsible if we can attribute a fault or credit to them for their action. .96

We also see "answerability models" which hold that the responsibility of an agent is connected to their capacity to be opened up to demands for justification from others ${ }^{97}$.

All of these views, social-attitude, ledger or answerability, can be used to contend that we should not blame individuals with psychopathic traits for their actions. If we admit that individuals with psychopathic traits are unable to appreciate the wrongfulness of their actions, accordingly it is not appropriate to blame them for their actions. Similarly, we ought not to fault them for their actions, or open them up to justify attitudes beyond their control.

Many philosophers have discussed psychopathy and moral responsibility. Neil Levy ${ }^{98}$ offers the argument, which will be discussed in greater detail below, that the individual with psychopathic traits' inability to use mental time travel, or episodic memory, shows that they ought not to be held fully responsible for their actions, as their actions do not have the right sort of moral content.

\footnotetext{
94 Eshleman "Moral Responsibility"

95 Eshleman "Moral Responsibility"

${ }^{96}$ Eshleman "Moral Responsibility"

${ }^{97}$ Eshleman "Moral Responsibility"

98 Neil Levy, "Psychopaths and Blame: The Argument from Content" Philosophical Psychology, 27 no. 3 (2014): 351-367
} 
Additionally, Stephen Morse ${ }^{99}$ presents the argument that individuals with psychopathic traits are not rational in a very specific sense, namely with their capacity to show morality and concern for others. So, according to Morse, what this entails is that individuals with psychopathic traits do not have access to good reasons, as most do, why not to harm others. Because of this, only the fear of punishment keeps individuals with psychopathic traits from breaking the law, but it's been shown that individuals with psychopathic traits aren't concerned with potential punishment for their actions. ${ }^{100}$ If an individual is lacking in the necessary rational capacities to grasp morality, it is neither reasonable nor meaningful for rational thought or understanding to be expected of them. A child, for example, whose brain has yet to fully develop rational capacities, may not be expected to fully understand or follow the moral code. And, similarly for an adult, if it were shown that a type of disability caused a decrease in rational capacities, it would be equally understood why that adult did or does not follow the moral code.

Paul Litton ${ }^{101}$ also discuses rational capacities in a similar vein to Morse, however his argument is even stronger. Litton claims that individuals with psychopathic traits possess not only a diminished capacity for moral reasoning, but also a diminished capacity for rational self-governance, and this is in large part due to their weak capacity to possess evaluative standards ${ }^{102}$. He argues that although

\footnotetext{
99 Stephen J. Morse, "Psychopaths and Criminal Responsibility" Neuroethics 1, no. 3, (2008): 205-212 100 Thomas Nadelhoffer and Walter Sinnott-Armstrong, "Is Psychopathy a Mental Disease?" in Neuroscience and Legal Responsibility, ed. Nicole A. Vincent (New York: Oxford University Press, 2013), 235

${ }^{101}$ Paul Litton, "Responsibility Status of the Psychopath: On Moral Reasoning and Rational SelfGovernance" Rutgers Law Journal, 39, No. 349 (2008) 349-391

102 Litton, Responsibility Status of the Psychopath", 375
} 
individuals with psychopathic traits do appear to be goal-oriented concerning their desire to achieve excitement and pleasure, he also distinguishes an important difference between the effort to satisfy one's desires, and one's efforts to live up to evaluative standards ${ }^{103}$. Typically, he contends, people do not simply act out on their first order desires. Instead, they contemplate and reflect on the worth of this desire, and decide whether it is worthwhile to act on it ${ }^{104}$. Litton points to example of a parent, deeply annoyed by their child's incessant crying. Despite her desire to strike or scream at the child, she knows better than to act upon it. Contrastingly, individuals with psychopathic traits do act on their first order desires, and lack the reflective capacities to evaluate their desires. Further, Litton argues, the negative emotions we feel toward ourselves when we don't meet our own standards, such as guilt, shame and remorse, are foreign to the person with psychopathic traits ${ }^{105}$. In other words, we typically express negative emotions toward ourselves when we don't perform in such a way that we've expected ourselves to hold up to. Individuals with psychopathic traits, however, don't experience these emotions, and although they may experience superficial frustrations and anger, these feelings are not representative of a deeper appreciation for evaluative standards ${ }^{106}$. Finally, Litton points to the fact that individuals with psychopathic traits do not act in ways that seem conducive to their happiness or freedom. He references cases of individuals with psychopathic traits studied by both Hare and Cleckley, which discuss how individuals with psychopathic traits, despite their desire to no longer be

\footnotetext{
${ }^{103}$ Litton, Responsibility Status of the Psychopath", 377

104 Litton, Responsibility Status of the Psychopath", 377

105 Litton, Responsibility Status of the Psychopath", 378

106 Litton, Responsibility Status of the Psychopath", 379
} 
incarcerated, continuously reoffend and find themselves imprisoned again. This occurs so frequently that compared to their counterparts, individuals with psychopathic traits are three times more likely to recidivate, and four times more likely to recidivate violently.107

Morally praiseworthy actions are not often contested; it is often easily recognizable to most people what a good deed is. A philanthropic person, who donates to those in need for no purpose other than to help those people, could easily be considered morally praiseworthy. In the same vein, morally blameworthy actions are not often questioned either-harming another person or their property or placing someone in harm's way are all good examples of uncontestably "bad" actions. The problems arise from the agents who commit these actions. For example, can a person who donates money only to give the appearance of being morally good truly be praised? While the action of donating money is nonetheless a morally praiseworthy action, our judgement of the person's motivations can affect our impressions on whether or not we determine that the person is deserving of the moral praise. Similarly, while most would not disagree about what a morally blameworthy action is, the question of moral blame lies in whether or not the individual is due to be subject to that blame. While generally, people accept that killing is wrong—and some will argue that killing, in any capacity in wrong-there are few caveats that make the person who did the killing not due for legal blame. For example, an executioner for the United States government mightn't be considered blameworthy for giving a lethal injection to a child murderer. A soldier at war, while

107 Litton, Responsibility Status of the Psychopath", 382 
killing many would not necessarily be considered morally blameworthy for killing these people, so long as they were enemy soldiers and not civilians or allied soldiers. Doctors who end the lives of patients with chronic illness, from the right to die movement, might not be considered morally wrong. All three of these cases could arguably go one way or the other-the individual could be morally blameworthy to some, and not to others, depending on who is asked. So, deciding who is morally blameworthy and who is morally praiseworthy can be a difficult decision to make.

First, degrees of responsibility are taken into account; how blameworthy is the agent? Did they commit a petty crime (i.e. steal from a convenience store), or did they commit a major crime (i.e. armed robbery with a deadly weapon)? Legally and morally, the degree of responsibility will fluctuate greatly depending on the action. The petty criminal may not even go to prison, especially if this is their first offence, whereas the major crime offender could be facing a minimum of 4 years incarcerated ${ }^{108}$. Similarly, we likely place much less moral blame on the petty crime than the major crime. And, most people would not object that the punishment or blame should fit the crime. Other ways that we may see degrees of responsibility would depend on the agent themselves. If there is a reason that the agent may not have been in full control of their actions or of their mind, then they may not be held fully or at all responsible for their actions. Although not all criminals that are held criminally responsible for their crimes are necessarily considered morally responsible by all—or even most—-the converse, that those held not criminally

\footnotetext{
108 Emily Blake, "Mandatory minimum sentence not unconstitutional for Hay River armed robber, says judge," CBC, March 27, 2018, https://www.cbc.ca/news/canada/north/mandatory-minimumsentence-robbery-firearm-1.4594867
} 
responsible are typically agreeable candidates to not be held morally responsible for their actions tends to be true. Based on how the legal system acts, those who shouldn't be held criminally responsible are individuals that are incapable of grasping or fully appreciating the gravity of the harm that they are committing. Some mental illnesses and some children, depending on age and the particular child, fall within the breadth of offenders who do not qualify for criminal responsibility.

\section{Theories on Amorality}

Equally important to understanding morality is to understand what the absence of morality would amount to: amorality. When individuals with psychopathic traits are described as amoral, it obviously means that they lack morality. But that doesn't tell us very much about what exactly the psychopathic person lacks when they lack morality and empathy.

One key trait that an amoral individual lacks, according to Neil Levy, is a strong conception of personhood-in the sense that a person's ability to relate back to and comprehend the basic desires, goals and ambitions of other humans is directly related to their capacity to empathize with others. Neil Levy ${ }^{109}$ suggests that in fact individuals with psychopathic traits completely lack an understanding of personhood and therefore cannot relate to others in a more traditional fashion, as a non-psychopath would. Levy's core argument on personhood and personal identity in terms of psychopathy is that because psychopathic individuals don't experience

${ }^{109}$ Levy, "Psychopaths and Blame, 362 
those same, seemingly intrinsic emotions and desires that most non-psychopaths experience, it couldn't be possible for the psychopathic individual to understand this variety of personhood the same way that the non-psychopath does. These emotions and desires include, of course, empathy, but also simply the desire to see all other people succeed in their pursuit of happiness-which is why we love a good "underdog story". Put simply, just as we try not to cause harm to others, we also enjoy seeing others succeed. Further, we feel an unspoken connectedness with other persons which is where these desires not to harm or see succeed come from. Naturally, we are inclined to feel closeness with those who are of the same species as us. From Levy's argument, the point is that individuals with psychopathic traits do not feel any which way about whether another person is harmed nor if they succeed, or do they feel the natural inclination to feel closer to other humans. Due to this deficit, individuals with psychopathic traits cannot reasonably be expected to connect to people in the same way that non-psychopaths do, but crucially, can also not be expected to fully understand the deeper meaning and affect that is accompanied with harming a person. I'll use an example to clarify this. Suppose an astronaut is exploring outer space, and discovers an alien society that has completely different mores, conventions and mannerisms from humans. Even if the aliens explained these customs to her, they would be completely foreign, and following these rules might seem arbitrary and pointless, aside from trying to appease the aliens. And further, she would likely have a terribly hard time understanding what it means to be one of these aliens, or what ideas and opinions seem to typically be intrinsic to them. Even if the astronaut were to follow the 
seemingly arbitrary laws, it would be unlikely that she would truly be able to mean it when she did. The concept of authenticity as previously discussed, is important, because when a psychopathic person is simply parroting information during an interview—or, they are inauthentic — it tends to signify that the information being parroted is not of genuine concern to them. In other words, when a person with psychopathic traits repeats back to a researcher or interviewer that causing harm to another person is morally wrong and the researcher deems that the psychopath is being disingenuous, the psychopath's moral depravity seems to only increase.

Returning, then, to the example of the astronaut, she will be caught in a dilemma regarding how she chooses to obey their laws and morals. Either she will be seen as delinquent and amoral if she chooses not to follow their laws, or if she chooses to follow their laws, but isn't authentic (as she is unable to), she will still be seen as delinquent and amoral. Our idea of morality seems to necessitate that we have some sort of genuine, pure meaning/motivation behind our actions, or else they lose their moral standing. For example, we might not find someone quite as caring and altruistic if we were to find out that they donate to charities only for the tax breaks. So in order for a person or an action to be considered morally upstanding, it must have been done so through a true, honest understanding of the reasons why said action is morally praiseworthy. This means that in order to be or act in a morally permissible way, one must not only possess knowledge of morals, but also possess knowledge how. The two can be distinguished by differentiating between knowledge about something versus actual, practical knowledge on how to complete a given task. For example, I have knowledge of tire changes; I know that 
the tires need to be changed before and after winter, but at the same time, I also possess the necessary knowledge on how to physically change the tire. In terms of morality, a person must not only understand that $x$ is morally praiseworthy, but must also know how to react to morally praiseworthy actions. Further, a morally competent person must not only understand that $y$ is morally blameworthy, but also know how to react to morally blameworthy actions.

According to this argument, because of the deficits that individuals with psychopathic traits possess, it's impossible for them to appreciate the full scope of harm that they may cause as a result of their crimes. The appreciation of the harm they cause can be compared to how humans treat non-human animals. Most people, vegetarians and vegans excluded, don't give much thought to the quality of life or living conditions of the animals that they eat. Even the people that are aware of this don't take it seriously enough to stop eating meat. It's because humans don't see non-human animals as something that they can empathize with. We may feel sympathetic toward the animals that are locked up and kept in cages, but being humans we don't have access to what pain a cow, chicken or pig is feeling-and subsequently, by definition, we cannot empathize with their pain. Our inability to empathize with these creatures makes it easier for us to be much colder and disconnected from them, essentially feeling unaffected, or nearly unaffected, by their being killed for human consumption. 
Andrew Vierra ${ }^{110}$ endorses Levy's view, and also builds on it to strengthen its point. Vierra agrees that individuals with psychopathic traits are deficient in mental time travel, and makes a point to use "sufficient empirical evidence"111, as Levy does not provide this, and seeks to use neurobiological evidence to cement Levy's argument.

Vierra cites how researchers have found several neurological abnormalities within unsuccessful psychopaths. First, Vierra notes, "the majority of brain areas that comprise the default network are either structurally or functionally atypical in [unsuccessful] psychopaths"112. Researchers have hypothesized abnormalities in the ventral medial prefrontal cortex (vmPFC), which could explain their impulsivity, or lack of foresight. When brain trauma results in damage of the vmPFC, aggressive, impulsive and reward-driven behaviour is observed. ${ }^{113}$ Researchers have also observed areas in the brain that comprise the medial temporal lobe to have abnormalities, including asymmetries in the anterior hippocampus, reduced hippocampal and parahippocampal cortical volumes. Additionally, they've observed decreased activity in the posterior cingulate gyrus, within fMRI scans of psychopaths encoding, rehearsing and recognizing words ${ }^{114}$.

From this data, Vierra puts forth the argument that individuals with psychopathic traits suffer from a deficit in mental time travel, and should therefore be afforded a mitigated attribution of responsibility. He arrives at this from Levy's

\footnotetext{
110 Andrew Vierra, "Psychopathy, Mental Time Travel and Legal Responsibility" Neuroethics, 9 (2016): 129-136

111 Vierra, "Psychopathy, Mental Time Travel and Legal Responsibility", 131

112 Vierra, "Psychopathy, Mental Time Travel and Legal Responsibility", 131

113 Vierra, "Psychopathy, Mental Time Travel and Legal Responsibility", 131

114 Vierra, "Psychopathy, Mental Time Travel and Legal Responsibility", 131
} 
argument that contends that we ought to judge an actor by the content of their action. However, Vierra recognizes that this argument can be deflected in many ways, such as rejecting Levy's definition of moral responsibility, or of his definition of personhood/its relevance to moral responsibility ${ }^{115}$. Instead, Vierra takes a legal route that sidesteps the possibility of being rejected on these grounds.

Vierra argues that per Miller v Alabama ${ }^{116}$, juveniles are not held fully responsible for their actions, as juveniles are shown to not have fully developed neurobiological structures. In fact, they possess the same types of issues with mental time travel as individuals with psychopathic traits do. So analogously, we ought to give individuals with psychopathic traits at least the same considerations as juveniles do, or hold both individuals with psychopathic traits and juveniles to the full force of the law.

\section{Knowledge That, How, and Why}

A popular set of terms in the epistemological space is propositional knowledge/knowledge that versus practical knowledge/knowledge how. Generally, knowledge that refers to when an individual possesses knowledge about something, like knowing that the density of water is $997 \mathrm{~kg} / \mathrm{m}^{3}$. Knowledge how, on the other hand, can be said to be "when it is truly said of you that you know how to do

\footnotetext{
115 Vierra, "Psychopathy, Mental Time Travel and Legal Responsibility", 133

116 Miller v. Alabama, 567 U.S. 460 (2012)
} 
something"117_such as how to ride a bicycle. On top of propositional and practical knowledge, we can also possess knowledge why. Knowledge why differs from propositional knowledge simply; while propositional knowledge entails knowledge about something, knowledge why entails knowing why that thing is. For example, while Lily knows that the sky is blue, she may not know why the sky is blue. Her lacking of why the sky is blue does not discount from her true knowledge that the sky on earth is blue. Lily may lack the necessary information on how the molecules in the air reflect more blue light from the sun than red light. Lily may also have learned this in a science class, but still not fully understand the concept of molecules, or how they can reflect light. In either situation, it would be said that Lily does not possess knowledge why the sky is blue, even if she knows that it is from the reflection of molecules.

The suspected issue with individuals with psychopathic traits is that although they possess the knowledge of or about morals (they know that $\mathrm{p}$ is morally wrong), upon deeper evaluation it's found ${ }^{118}$ that they don't actually understand why or how something is morally praiseworthy or blameworthy, and they also do not know how to react to morally praiseworthy or blameworthy actions. Because of this, and because we require authenticity when it comes to morality, individuals with psychopathic traits have little hope of ever being considered moral persons. In fact, the problem with anyone lacking know-how suggests, as discussed earlier in the description of empathy, begs the question of

\footnotetext{
117 Jeremy Fantl, "Knowledge How", The Stanford Encyclopedia of Philosophy (Fall 2017 Edition), Edward N. Zalta (ed.), https://plato.stanford.edu/archives/fall2017/entries/knowledge-how/ 118 R.J.R Blair, "A cognitive developmental approach to mortality: investigating the psychopath" Cognition, 57 (1995): 1-29
} 
whether a true, practical appreciation of the task in question is present. For example, many mothers and fathers will say that until one's actually had a child of their own, they have no idea what raising a child is like. While in theory, most people can grasp a pretty straightforward and similar idea on how to care for a child such as taking care of their basic needs, educating them, loving them and so forth, to actually raise a child will prove quite different. That is, the knowledge how to raise a child, the practical knowledge, can only be acquired from first hand experience. So, it's not an unfair claim to posit that those who are childfree by choice ${ }^{119}$ lack knowledge how to raise a child—and, assuming they remain childfree, always will. Further, this lack of know-how may necessitate that the individual cannot appropriately appreciate the practical knowledge; say perhaps, a childfree couple doesn't understand why their friends who have children never have any energy to socialize, or if they mistakenly assume raising a child is easy, without the knowledge on how to do so. So, similarly with other individuals incapable of accessing knowhow of various kinds, whether by choice or due to a deficiency, these issues could also arise.

Although the link may not always seem clear, morality and the legal system are interconnected. Specifically, in the ideal legal system, we would find the same individuals both legally and morally responsible. In this next section, I will offer an outline of the current punishment standards in the United States and Canada.

\footnotetext{
${ }^{119} \mathrm{~A}$ growing population of individuals is embracing the 'voluntary childlessness' lifestyle, where, as the name suggests, they choose to live without raising any children. Articles such as the following discuss this notion:

Rosemary Gillespie, "Childfree and Feminine: Understanding the Gender Identity of Voluntarily Childless Women." Gender and Society 17, no. 1 (2003): 122-36.
} 


\section{Current Punishment Standards}

Currently, the United States and Canada use very specific standards on how to punish offenders. First, an accused will either be found guilty or not guilty. Recall in the first chapter we discussed the elements necessary for a crime. These are mens rea and actus reus (criminal intent and criminal act, respectively). If it can be shown that the offender did not have one or both of these elements present during the crime, they will have to be found not guilty. Ways that an offender may not have intended to commit a crime can be highly varied. If the individual was under duress, for example, there will be no contest that they committed the act, but if they were being forced against their will to commit a crime they cannot be held responsible for that crime. Also, an offender may not be responsible if they are acting in self-defence or in the defence of another person, and the intention was to save themselves/the other person, not to commit a crime. Finally, a person could be found not guilty for a crime if they suffer from a mental illness. Pleading insanity, as it's known in the United States, or not criminally responsible due to mental disease in Canada, is not an easy process; very few offenders (about 1\%) use that defense in a court, and only about one quarter of said defenses are successful ${ }^{120}$. That being said, having this type of defense is highly important for ensuring that all people are ensured their right to a fair trial. From the same thought that a child should not be considered

\footnotetext{
120 Virginia Department of Behavioural Health and Developmental Science "The Insanity Defense and the NGRI finding" accessed July 31, 2019, http://www.dbhds.virginia.gov/library/forensics/ofo\%20$\% 20$ section $\% 201 \% 20$ all\%20sections.pdf
} 
criminally responsible for an offence, nor should those with certain mental illnesses. The rationale behind insanity rulings is such that if it can be proved that the offender was not in their right mind during the time of the crime-meaning that they did not know that what they were doing was legally wrong, were unable to appreciate the wrongfulness of the crime, or, did not even know what they were doing - then they should not be held culpable in the same way as an offender fully aware of their actions and the legality surrounding them. Further, being found not guilty for mental health reasons does not necessitate that the offender will be walk free post-trial. If the judge determines based on a doctor's recommendations that the individual poses a threat to themselves or to others, then the individual faces the potential of involuntary civil confinement. Some controversy surrounds civil confinement, as the time spent confined is not based on a sentence, such as 10 years, but instead, by when the doctors at the facility determine that the individual no longer poses a threat to themselves or to others. The notion often encouraged by media and popular culture that offenders are being let off the hook when making the insanity plea is a misunderstanding of the proceedings that follow such a verdict. Those critics do not realize that although the traditional standards of punishment are not met for those who successfully use the insanity defense, it is also not an exit strategy, as an admission of guilt is required.

For cases where the insanity defense is not applicable within criminal trials, the accused typically has their case presented to a jury of their peers who will find the defendant either guilty or not guilty. If the jury finds them guilty, then they will be sentenced to that crime. The way an offender acts during sentencing along with 
their criminal history can also prove highly important for their fate. For example, first time offenders might not get the maximum possible sentence, but the decision is ultimately up to the judge's discretion. ${ }^{121}$ Factors that can help reduce the sentence of an offender are called mitigating factors. Along with first time offences, other mitigating factors include: a minor role played in the crime, provocation or stress that explain the crime (but not excuse it) and genuine remorse. ${ }^{122}$ So, although the offender has been found guilty, there are certain ways that offenders can present themselves to, essentially, seem more appealing to a judge. For example, in a recent Supreme Court case, $R v v$ Suter ${ }^{123}$, the judge took into account the fact that the defendant had "strong community support and the fact that he has been a productive member of society"124

Conversely, certain facts or circumstances can be considered aggravating factors, which prosecutors will use during sentencing to suggest a harsher punishment for the crime. ${ }^{125}$ Among many others, some aggravating factors include recidivism, lack of remorse, victim's vulnerability, if the crime had been committed in front of a child and if the offender is recognized as a psychopath. ${ }^{126127}$ This means that as it currently stands, if a clinical professional determines that an offender is

\footnotetext{
121 "Mandatory Sentences of Imprisonment in Common Law Jurisdictions: Some Representative Models" Canada's Justice System, Department of Justice, last modified June 3, 2019, https://www.justice.gc.ca/eng/rp-pr/csj-sjc/ccs-ajc/rr05_10/p2.html

122 Aggravating and Mitigating Factors", Criminal Law, Justia, Accessed July 24, 2019, https://www.justia.com/criminal/aggravating-mitigating-factors/

123 R. v. Suter, 2018 SCC 34, [2018] 2 S.C.R. 496

124 R. v Suter

125 Justia, "Aggravating and Mitigating Factors"

126 Aggravating Factor,” Legal Information Institute, Cornell School of Law, Accessed July 31, 2019 https://www.law.cornell.edu/wex/aggravating_factor

127 Morse, Psychopaths and Criminal Responsibility", 208
} 
psychopathic, it will likely be taken into account during sentencing for a harsher sentence for the psychopath.

In R.v. Suter, it seems feasible that if he'd been a different type of person, perhaps not a large part of his community, or not well known, or did not seem to convey as much heartfelt guilt and sorrow, then Mr. Suter would have received a heavier sentence.

While some aggravating and mitigating factors seem reasonable-in particular, receiving a more lenient sentence for a first-time offense, many others are troubling and verge on prejudicial. It hardly seems just to reward behaviours completely irrelevant to the case; justice is supposed to be blind, and it should therefore be blind to a person's character as well, rather than rewarding them for being a good person outside of their legal malfeasance. More importantly, if a person is not a good person outside of their legal malfeasance, there is no good reason to punish them such that they are not being afforded benefits that their counterparts receive. The offender's character does not change whether or not they have committed the crime, and so focusing on this factor during sentencing seems pointless. It is, however, important to note that one could raise an objection at this point, regarding the sentencing of a person with psychopathic traits. According to Canada's criminal code, the purposes of sentencing are to, "a) to denounce unlawful conduct and the harm done to victims or to the community that is caused by unlawful conduct; b) to deter the offender and other persons from committing offences; c) to separate offenders from society, where necessary; d) to assist in rehabilitating offenders; e) to provide reparations for harm done to victims or to the 
community; and f) to promote a sense of responsibility in offenders, and acknowledgment of the harm done to victims or to the community"128. Therefore, taking one's character into consideration could be helpful, given the frequency of recidivism seen in offenders with psychopathic traits. However, this concern needn't apply to individuals with psychopathic traits, at least not in the capacity that it currently does; an individual with a mental illness that precludes them from criminal guilt would certainly not have the likelihood of their recidivism considered, because they would never have reached this part of a trial. This should be equally true of individuals with psychopathic traits. Their character would still be taken into consideration during psychiatric assessments if they were facing civil confinement, but much less is at stake for the offender at that point.

Another unjust element of aggravating and mitigating factors is the offender's level of guilt. While admittedly, Canada is focused on the rehabilitation of convicted criminals, it is both unfair and unrealistic to search out genuine remorse at a sentencing hearing, when an offender is trying to receive the lowest possible sentence that they can. Further, just the same with the offender's character, their feelings of guilt or remorse do not change the fact that the crime has been committed.

Lastly, and perhaps most importantly, it is discriminatory to afford those with rational capacities toward feelings of guilt and remorse when there are individuals who are incapable or have lessened capacity to feel guilt or remorse. Affording benefits to one group when another group is unable to meet the requirement will

${ }^{128}$ Criminal Code, RSC 1985 , c. C - 718 
always be wrong. In R. v. Suter, the judge cited that Suter's immense grief played a role in his sentence being reduced. We can then gather that had he not been as remorseful, Suter's appeal may have been overturned. We need to ask, what if Suter did not have access to the capacities that let him feel guilt? Or, imagine a more abstract example where two people commit the same crime. Neither person has been convicted of a crime prior to this. Person A is a PTA member at the local school, and volunteers at the local church a few times a month. Person B works at a local hardware store and is not involved with the community. At each of their sentencing hearings, Person A reads a long, articulate, heartfelt statement of regret while Person B does not read anything. Person A is sentenced to 4 months (the minimum sentence) and Person B is sentenced to 26 months (the maximum sentence). With both crimes being equal and both people being first-time offenders, the mitigating factors of community involvement and remorse have played into Person A being given a far lighter sentence, while Person B, who mightn't have the same opportunities, or spare time to volunteer, or mightn't possess the rational capacities to understand feeling genuine remorse, has been given the maximum sentence. And again, while rehabilitation of offenders is highly important, I don't believe that sentencing is the proper place to be judging how far the offender has been rehabilitated, as it's clear some people may receive preferential treatment that others do not have access to. Further, even if Person B did not have any circumstances that kept them from being active in the community or being remorseful, I believe it could be argued that it's nonetheless unjust to use these mitigating factors to shorten a prison sentence. After some time in a correctional 
facility, at parole hearing is the more appropriate time to review reducing a sentence, as at this point the offender would have had more than just the time between arrest and trial to reflect on their actions and enrich themselves as a person. 


\section{Chapter III}

\section{Epistemic Injustice}

In this next Chapter, I will discuss Miranda Fricker's concept of Epistemic Injustice, explaining what it is, who suffers from it and how it relates to individuals with psychopathic traits and their criminal responsibility.

\section{What is Epistemic Injustice?}

Miranda Fricker introduces the concept of epistemic injustice in her book "Epistemic Injustice: Power and the Ethics of Knowing”. In it, she describes a type of injustice that is "a wrong done to someone specifically in their capacity as a knower"129. For epistemologists, a knower is simply an individual who knows or apprehends something.

Fricker is referencing a very specific type of prejudice, one which is epistemic in nature, meaning one can suffer as a knower, someone with knowledge to share, or if conceptual resources are unavailable to the knower to understand a specific event or experience. If a hearer has deflated reception toward the speaker, then the speaker will have suffered from epistemic injustice.

To make this concept clearer, let's use an example to conceptualize. Picture Heather, a young woman starting off in a new career as researcher at an advertising

\footnotetext{
129 Miranda Fricker, Epistemic Injustice: Power and the Ethics of Knowing Oxford: Oxford University
} Press, 2007), 1. 
firm. At the time of her hire, two other people, Mark and John, were also hired as researchers. Heather's company focuses on traditional family values, meaning that many of their advertisements solely depict heterosexual couples, women being the sole caretakers of home and children, "boys will be boys" attitudes, and so forth. The company does not discriminate in its hiring process, although they seem unaware of their out of date ad campaigns. Heather's job focuses on looking into new products that consumers would be interested in. During her research, Heather discovers that many people are disapproving of the company's ads because they do not seem inclusive and some of their ads verge on offensive. Heather decides to further investigate this, and finds that over half of the people that she surveyed agreed that the company's ad campaigns do not represent or speak to them as consumers. Baffled from her findings, Heather decides to take note of what she has learned and decides to bring it up to her boss during a monthly meeting held with herself, her boss and the other two male researchers. At the meeting, both coworkers bring up suggestions to the boss that he takes wholeheartedly into consideration. When it is Heather's turn to speak, she explains how she believes that the company could benefit from introducing new, more inclusive advertisements, and how many people that she personally surveyed did not feel represented. After explaining all of this to her boss, her boss tells her that there is nothing wrong with the advertisements that they create, and suggests that because she is of the "gentler sex", perhaps she has felt overly sensitive about the issue, and tells her to try to think more clearly after she has calmed down. He also suggests that she should be focusing on more "femaleoriented" tasks, such as shopping, fashion and makeup trends. Embarrassed and 
frustrated, Heather seeks out someone at work who may share her experiences or understand. She explains that her boss made her feel uncomfortable and was rude, but can't quite put to words precisely what he did to her. Her coworker, although empathetic to her frustrations, does not recognize sexism in the workplace as an issue, as no workplace currently recognizes these issues. Heather is told instead that the boss is her boss for a reason, and that if he makes rude comments, that is just the way it goes.

While there are several dimensions of injustice involved with this example, I'll be focusing on the ones that are distinctively epistemic. What makes them particularly an epistemological wrong is that in the cases of epistemic injustice, the individual is being dismissed as a source of knowledge. Not only does the hearer miss out on information, but also the speaker will potentially have to suffer from the lasting effects of their dismissal. In Heather's example, after having her ideas dismissed with any real consideration and not having her issues recognized by her coworker, she may lose the confidence to speak out and give valuable information or ideas for the company in the future. Further, Heather's boss has missed out on valuable information about his company, that he completely dismissed.

Fricker describes two types of epistemic injustice that an individual can suffer from: testimonial and hermeneutical injustice. Testimonial injustice "occurs when prejudice causes the hearer to give a deflated level of credibility to the speaker's word."130 In other words, a speaker may suffer from testimonial injustice if the hearer judges them before or without hearing what they are saying. For

\footnotetext{
130 Michalis Kyratsous and Abdi Sanati, "Epistemic injustice and responsibility in borderline personality disorder," Journal of Evaluation in Clinical Practice (June 2016): 976
} 
example, if a hearer does not believe what the speaker has to say because of their sex, race, social class or any other prejudiced reason, they are committing testimonial injustice. Testimony is highly important to epistemologists, as it is one of the main ways that we transmit knowledge to one another and therefore a building block to all the knowledge we collectively posses. As opposed to the perhaps betterknown courtroom definition of testimony, epistemological testimony refers to a way that people can transmit knowledge. For example, when person A asserts, tells, or says something to person $\mathrm{B}$, it can be said that the knowledge shared by person A is testimony. ${ }^{131}$ To recognize that an individual has testimony to share is therefore recognizing that they have knowledge that they can transmit to you. Conversely, failing to recognize that they have testimony to share signifies that you do not recognize that the individual has knowledge to share with you. So, when one makes the inappropriate assumption that an individual lacks any testimony to share based on their identity, it's evident that they are causing a type of injustice to that individual. Not only are they denying the person their opportunity to share their testimony, but also that individual may miss out on important information as a result of their ignorance. Returning to the example from above concerning Heather in the workplace, testimonial injustice would have occurred during the meeting Heather had with her boss. When Heather attempted to share her testimony that a large number of consumers were disapproving of the ad campaigns, her boss immediately turned her down, without really taking in what she had to say. With his

\footnotetext{
${ }^{131}$ Jonathan Adler, Edward n. Zalta (ed), "Epistemological Problems of Testimony," Stanford Encyclopedia of Philosophy, last modified April 17, 2017, https://plato.stanford.edu/entries/testimony-episprob/\#NatTesEpiVul
} 
denial of her testimony, Heather suffers from being treated as a lesser, based solely on her identity.

Testimonial injustice is also related to prejudice of identity—we will return to the concept of testimonial injustice below in the discussion on repugnance.

Hermeneutical injustice occurs at an earlier stage than testimonial injustice. This form of epistemic injustice occurs when concepts are collectively poorly understood by society, or sometimes not yet recognized, and thus, the lack of understanding bars the individual who is target of the concept in question from the proper help, support or resources that they might need to make sense of or navigate their situation. Without the hermeneutic or interpretive resources available, the individual will be left without having their injustice properly addressed. Returning to the example from above, hermeneutical injustice would have occurred during her meeting with her coworker. When Heather was unable to explain precisely what about her boss made her uncomfortable, it was because collective understanding for sexism, specifically in the workplace, did not exist. In typical North American workplaces, when hostile work environments are created, the employee is at least disciplined, if not terminated. However, because nothing was done in Heather's case, it is clear that this company and social climate does not yet recognize gender inequality. Because of this, Heather is forced to suffer with the lasting effects caused by having her concerns cast aside because of her gender.

For Fricker, the importance lies in the individual suffering from the injustice not completely understanding why there is something wrong with how they've been treated, as well as their experience being "obscured from collective 
understanding". ${ }^{132}$ Another example that is used by Fricker is the case of Carmita Wood, a female who joined the workforce during a time when most workplaces were male-dominated, and as such, the term "sexual harassment" had not yet come into existence. Wood had dealt with many sexual advances from her boss until she felt she had no other choice but to quit her job. Afterwards, she submitted a claim for unemployment insurance but was denied because she could not come up with an adequate reason as to why she left her job. Wood's struggle to place words to the experience in her workplace is the heart of hermeneutical injustice; "sexual harassment" not yet being a term that employees could reference essentially barred Wood from being able to properly express her experience. Fricker argues that until the term sexual harassment would be created and more women could understand and place their experiences, situations such as Wood's would inevitably bring about epistemic injustice. Once a collective understanding was established, Wood and other women who suffered from similar experiences could face validation and understanding, effectively giving them "cognitive confidence"133—a term coined by Fricker, in their experiences as sufferers of injustice.

However, Philosophers such as Laura Beeby ${ }^{134}$ have raised concerns about this type of epistemic injustice. The concern lies in whether hermeneutical injustice is truly an injustice that is distinctively epistemic in nature. Beeby takes the example of Carmita Wood to illustrate her example. In the Wood example, if it was the case that she did not have the words to describe her experience, and this is because the

\footnotetext{
${ }^{132}$ Fricker, Epistemic Injustice, 154

${ }^{133}$ Fricker, Epistemic Injustice, 148

${ }^{134}$ Laura Beeby, "A Critique of Hermeneutical Injustice" Proceedings of the Aristotelian Society 111, (2011): 479-486
} 
collective societal norms did not yet recognize sexual harassment, then the harasser, Wood's boss, equally did not know what sexual harassment meant. It seems obvious to Beeby, however, that Wood was significantly more disadvantaged than her harasser, and asks why this is the case. The conclusion she comes to is that the background societal conditions, such as sexism, are the cause of the greater disadvantage. Therefore, Beeby argues, Carmita's experience is not distinctively epistemic, as the background societal conditions are causing the difference in injustice between herself and her harasser ${ }^{135}$. The example with Wood should illustrate, Beeby believes, how hermeneutical injustice is generally too reliant on societal conditions such as sexism or racism, and because of that, cases of so-called hermeneutical injustice should not be considered cases of epistemic injustice.

While I believe Beeby raises an important point concerning hermeneutical injustice, I also believe she's missed some important aspects of the Wood case. First, while sexual harassment was not a term in the 1970s workforce, laws against crimes of a sexual nature existed. From a legal standpoint, her boss would have been aware that imposing himself sexually upon a woman without her consent was impermissible. Just as Carmita knew that what her boss was doing was wrong, as it led to her feeling forced to quit her job, her boss would have known that the way he was treating her was wrong-but due to the power imbalance between sexes, he just didn't care.

Second, from the example it seems that the hermeneutical injustice suffered by Wood is not simply that she does not have a description for her experience in the

135 Beeby, A Critique of Hermeneutical Injustice 483 
workplace, otherwise the moment she suffered the hermeneutical injustice would have been when she failed to find an appropriate reason to give for why she was quitting. Instead, the injustice was suffered when she was trying to make a claim for unemployment insurance, but couldn't come up with a sufficient reason. So, Carmita is not at an equal cognitive disadvantage as her harasser, because the consequences of her harassment have persisted.

Third, I don't necessarily agree that relating background societal conditions takes away from the distinct epistemic nature of the injustice. Perhaps the injustice suffered by Carmita is done to her specifically as a female knower. In Wood's case, she entered the workforce in 1970s America when most jobs were male-dominated. The collective understanding of women's rights, specifically as workers, was therefore not established in a way that it is today. So, as a result of this, women as knowers would have been at a disadvantage. To further the point, until later in the 1970s, women could be fired from their jobs for becoming pregnant ${ }^{136}$. Today in the United States, the Pregnancy Discrimination Act ${ }^{137}$ prohibits employers from discriminating against a woman for becoming pregnant, but prior to this act coming into force, the collective understanding of pregnancy rights would not have been as thoroughly understood or recognized.

In addition to the two types of epistemic injustice discussed above, several authors have expanded on Fricker's work and suggested other ways in which people

\footnotetext{
136 "Maternity (and Paternity) Leave and Pay," Rights and Responsibilities, Striking Women, Accessed July 24, 2019, https://www.striking-women.org/module/workplace-issues-past-andpresent/maternity-and-paternity-leave-and-pay 137 "Pregnancy Discrimination," About EEOC, U.S. Equal Employment Opportunity Commission, Accessed July 24, 2019, https://www.eeoc.gov/eeoc/publications/fs-preg.cfm
} 
can suffer from epistemic injustice. For example, Katherine Hawley has proposed that individuals can suffer from epistemic injustice in relation to knowledge how. Recall, typically in epistemology two types of knowledge are discussed: knowledge that, or propositional knowledge (I know that to ride a bicycle you must sit on the seat and pedal), and know-how, or practical knowledge (I know how to ride a bike). Concerning Fricker's categories, testimonial and hermeneutical injustice, are both associated with propositional knowledge. As Hawley remarks, it is important to identify ways in which people may suffer epistemic injustice in relation to practical knowledge, and yet, Fricker does not focus on practical knowledge in her book. This is unsurprising given the attention that Fricker places on testimony, Hawley reminds us ${ }^{138}$, as testimony is comprised of someone asserting $X$, it will always take space in the propositional knowledge realm. Be that as it may, Hawley seeks to establish cases where epistemic injustice could be tied with a person's practical knowledge. She first introduces four situations relevant to the transmission of knowledge. First is the apprentice ${ }^{139}$. The apprentice wants to learn how to do something from someone who knows how to do that thing. It can represented as:

A would like to know how to $P$

A wants B to either show or tell them how to $P$

The A here represents the apprentice seeking practical knowledge, $P$ represents some sort of practical knowledge and B represents someone they recognize to be an expert/knows how to exercise the practical knowledge. Next is the examiner

\footnotetext{
${ }^{138}$ Katherine Hawley, "Knowing How and Epistemic Injustice" in Knowing How: Essays on Knowledge, Mind and Action, ed. John Bengson and Marc A. Moffett, (New York: Oxford University Press) (2011): 283

${ }^{139}$ Hawley, "Knowing How and Epistemic Injustice, 285
} 
situation. ${ }^{140}$ The examiner situation occurs when one person is checking another's credentials on something that they know to be true. It looks like such:

\begin{abstract}
A knows $X$ is true
B has asserted $X$ is true

A asks B whether they really know $X$ to be true, or if they just believe it to be true.

Here, $X$ is representing some piece of true knowledge. The next situation is the inquirer situation ${ }^{141}$. In this situation, the inquirer seeks to gain knowledge from another person. It can be demonstrated as:
\end{abstract}

A is interested if B knows $X$, because A would like to know $X$ Here, the inquirer is represented as A, some knowledge to be transmitted is represented by $X$ and $B$ represents an expert that knows said knowledge. The inquirer situation is related to the apprentice situation, because if A learns that B knows how to $X$, then they can enter into an apprentice situation where B will show them how to X. Inquirer situations are where instances of testimonial injustice can occur-we'll expand upon this below

Finally, Hawley discusses the client situation ${ }^{142}$. The client situation is similar to the apprentice, but instead of being shown or told how to $P$, the client is seeking out someone, an expert, who can $P$ for them, it can be represented as "A wants B to $P$ for them". Additionally, in the client situation, A may know how to $P$, although they choose not to, whereas in the apprentice situation, A does not know how to $P$ until B

\footnotetext{
${ }^{140}$ Hawley, "Knowing How and Epistemic Injustice, 284

${ }^{141}$ Hawley, "Knowing How and Epistemic Injustice, 284

142 Hawley, "Knowing How and Epistemic Injustice, 287
} 
shows or tells them how to $P$. To use an example, I may have a pretty good idea what entails cleaning out my eaves-getting a ladder, using gloves and a good, sturdy broom to clean out old gunk and leaves-but that does not necessarily mean I have the time or desire to do so. Instead, I will choose to call someone dedicated to the field of cleaning eaves.

At this point, Hawley brings to question whether ability and know how are the same thing. This question is important, as it is key in differentiating the client and the apprentice. I'm not necessarily sold that all clients truly know how to do something, even if they have the ability. To return to the example with cleaning my eaves, although I possess the ability to climb a ladder and clean away leaves, I cannot say for certain if I would do a sufficient or efficient job at cleaning. Aside from this, I believe that whether or not A possesses the ability to $P$ is a moot point; they are seeking B to $P$ for them, and therefore will not $P$, even if they know how to. So, to me, the client situation is simply a variation of the apprentice where A seeks B to $P$ for them.

Hawley also points to other knowledge related to client situations, such as knowledge whether, where and knowledge when. We seek out others to help guide us on questions such as "when to invest in stocks", "whether to start eating immediately or not at a dinner party" or "where to buy a cheap but reliable car". ${ }^{143}$ All client or apprentice situations have the potential to become instances of epistemic injustice. Recall earlier, we touched upon how inquirer situations relate to epistemic injustice. With inquirer situations, when B tells $\mathrm{A} X$, they are making an

${ }^{143}$ Hawley, "Knowing How and Epistemic Injustice, 289 
assertion, or giving testimony. If A makes an inappropriate judgment about B, perhaps because they are a woman, or because they are of colour, and chooses not to believe B based upon this judgement, then A has committed testimonial injustice. Fricker describes indicator properties: detectable properties of potential informant that correlates with true beliefs ${ }^{144}$, such as social status. Meaning, someone with a higher social standing that tells me $X$ would seem more believable than someone with a lower social standing. Hawley calls this an upstream indicator of true belief. In the apprentice situation, we can analogously see that when A seeks B to show or tell them how to $P$, if they make the same types of unduly judgements of someone's ability because they are from a certain social group, this too should be considered a form of epistemic injustice. Take the example Hawley uses that I will expand upon, of a young man learning how to drive. He is waiting for his driving lesson, and he can see his instructor driving from far away coming to pick him up. Only after she pulls up to him, and he sees that she is a woman, does he say that because women cannot drive as well as men can, he would like a male instructor instead. Despite the fact that he witnessed the woman driving and the fact that she obviously has credentials as someone who knows how to drive, he has made a judgment based on the fact that she is a woman. Hawley uses "downstream indicators ${ }^{145}$ ", such as successful completion of an action, to denote indicators that make us more likely to believe a person possess knowledge how. However, as seen in our example, despite witnessing successful action, the boy still chose to believe that the female driving instructor did not possess satisfactory know-how.

\footnotetext{
${ }^{144}$ Hawley, "Knowing How and Epistemic Injustice, 292

145 Hawley, "Knowing How and Epistemic Injustice, 292
} 
Hawley argues that the epistemic injustice involved with knowledge how therefore lies in when downstream indicators are less susceptible from certain social groups ${ }^{146}$. Examples that Hawley uses include how when comparing blind orchestral auditions to normal auditions, more women were admitted during blinds compared to not. Additionally, she points to how both women and people of colour have to work harder to prove that their work performance is ability-based rather than sheer luck. Similarly with client cases, it isn't difficult to imagine cases of epistemic injustice. Perhaps, for example, a person does not want a Mexican plumber because he believes that Mexicans are lazy. Or, someone could be lost in a city, and trying to figure out whether they need to take the A train or the B train. They pass by many women, deciding not to ask any of them because they believe that women don't know or cannot give accurate directions. The injustice committed in either a client or apprentice case seems to be equally unduly, wrong and prejudiced, and this is the main reason I find client and apprentice cases to be similar enough to group together.

Acknowledgment of this branch of injustice is worthwhile, because there can be many lasting effects just like with other forms of epistemic injustice. For example, Hawley illustrates that when comparing blind orchestral auditions to normal auditions, more women were admitted during blinds compared to not. What can be inferred from this is that normally, fewer women pass their orchestral auditions, an audition that they would have spent a great deal of time and effort preparing for.

\footnotetext{
146 Hawley, "Knowing How and Epistemic Injustice, 294
} 
Following the failure, the student may lose the confidence or will to continue on in her practice.

While epistemic injustice related to knowledge how does not fall into either of Fricker's categories of epistemic injustice, Hawley has made it quite clear that people can be epistemically wronged based on their practical knowledge. It may be that Fricker will be required to add a new category that encompasses wrongs specifically related to one's practical knowledge.

\section{Who Suffers from Epistemic Injustice?}

Another example that Fricker draws upon is a case from the movie The Talented Mr. Ripley. In it, the female character Marge Sherwood is ignored and brushed aside from sharing valuable information of Ripley's murderous ways solely because she is a woman ${ }^{147}$. Fricker's main focus of epistemic injustice is women or other typically marginalized groups ${ }^{148}$ as these are the people whose voices are the last to be heard, or the most likely to be judged via stereotypes. As the central idea of epistemic injustice addresses individuals who may miss out on testimony due to their identity, it follows that groups who suffer from other identity-based injustices are, in general, at a higher risk for epistemic injustice. Recall, Beeby's concerns that hermeneutical injustice is too related with background societal conditions, and that hermeneutical injustice isn't truly a distinctively epistemic wrong. Regardless as to

\footnotetext{
147 Fricker, Epistemic Injustice, 14

148 Throughout the book, examples are made pointing to marginalized groups. Also, intuitively, these are the groups of people that aren't typically listened to.
} 
whether or not her concern is true, the point she makes about how hermeneutical injustice is strongly tied to background societal conditions demonstrates how many cases are associated with disadvantaged social groups.

Additionally, as discussed above, it can be said that there are varieties of epistemic injustice that are suffered by certain groups, such as hermeneutical injustice suffered exclusively by certain groups, be it women, blacks, Jews or other minorities. This does not mean that these are the only groups that can suffer from epistemic injustice. Virtually any person, regardless of race, sex, class age or physical ability has the potential to be wronged as a knower. Fricker takes time to flesh out and focus on the 'credibility economy'149. Credibility economy refers to the way in which we can gain or lose our credibility, depending on various factors. So, in this case, Fricker focuses on how stereotypes can corrupt the hearer's judgment of a speaker's credibility, ${ }^{150}$ making them unnecessarily lose credibility. As an example, perhaps John is distrusting of the black lifeguard at his local pool because he's heard that black people aren't proficient swimmers, and believes this regardless of the lifeguard's accreditations. John has thus reduced how credible he views the lifeguard's abilities and knowledge, solely based on negative stereotypes. And so, although any person could suffer from epistemic injustice, due to the credibility economy, typically those who are victim of negative stereotypes could lose some credibility due to said stereotypes.

Other authors have offered situations where epistemic injustice can come into play, that doesn't necessarily involve "typical" groups who suffer from

\footnotetext{
${ }^{149}$ Fricker, Epistemic Injustice, 30
}

${ }^{150}$ Fricker, Epistemic Injustice, 30 
epistemic injustice. For example, Carel and Kidd ${ }^{151}$ argue that epistemic injustice is prevalent in health care. Both testimonial and hermeneutical injustice are suffered by the ill and afflicted, according to them. They argue this, "Because they are often regarded as cognitively unreliable, emotionally compromised, or existentially unstable in ways that render their testimonies and interpretations suspect." ${ }^{152}$ In other words, similarly to the case of Marge Sherwood, Carel and Kidd argue that due to their illnesses, patients are at risk to be not taken seriously or may be unheard specifically because of the fact that they are ill. Carel and Kidd also argue that patients could suffer from hermeneutical injustice, because "the kind of experiences illness affords are often difficult to make sense of and communicate"153. In the credibility economy, patients are judged as being unable to give testimony due to stereotypes formed within the medical community. As a result, patients tend to lose some credibility that they would have initially held had they still been healthy.

Christopher Hookway ${ }^{154}$ also offers alternatives to who can suffer from epistemic injustice, exploring groups outside Fricker's framework. Hookway focuses on participants, such as in a classroom setting. He argues that, for example, a student who raises their hand can be dismissed by the teacher, when the student's question, comment or counterexample could have provided insight or added to the discussion. If the teacher treats the student as if they do not have the capacity to raise deliberative or thought provoking questions, then that student would suffer

\footnotetext{
${ }^{151}$ Havi Carel and Ian James Kidd "Epistemic Injustice in Healthcare: a Philosophial Analysis" Medicine, Healthcare and Philosophy, 17, no.4 (2014): 529-540

152 Carel and Kidd, Epistemic injustice in Healthcare, 530

${ }^{153}$ Carel and Kidd, Epistemic injustice in Healthcare, 530

${ }^{154}$ Christopher Hookway, "Some Varieties of Epistemic Injustice: Reflections on Fricker", Episteme, 7 no. 2 (2010): 151-163
} 
from epistemic injustice ${ }^{155}$. Similarly with issues in the medical field, the teacher, professor, or leader in the discussion group could possibly hold negative stereotypes about students that lead them to have a corrupted view of the student's credibility. For example, the disparity in both level of education as well as age or experience could cause the leader in this situation to view the students as less credible concerning bringing meaningful contributions to the discussion. Finally, a group that I argue suffers from both types of epistemic injustice is individuals with psychopathic traits. In the next section, I will outline exactly how they suffer from all types of epistemic injustice, as well as why it is so crucial to recognize that they do.

\section{Individuals with Psychopathic Traits and Epistemic Injustice}

Recall, that the United States' Model Penal Code excludes individuals with psychopathic traits from the insanity defense, as psychopathy is considered a risk factor for recidivism. This means that often, the individual with psychopathic traits' moral deficiency is used against them in order to argue for a harsher sentence. Assuming that unsuccessful psychopaths indeed suffer from a real deficit in morality or rational decision-making, the judicial system regularly commits grave miscarriages of justice in treating their deficit as an aggravating factor. Using one's condition against them as an argument for a more severe imprisonment term does not represent the fair and accessible justice system that all citizens deserve.

\footnotetext{
${ }^{155}$ Hookway, Some Varieties of Epistemic Injustice, 158
} 
It is evident that at this point, the underpinnings of psychopathy are yet to be fully understood. For example, as it stands, psychopathy is not included in the DSM. A very similar personality disorder, ASPD is included in the DSM. ASPD—antisocial personality disorder-is sometimes also known as sociopathy, is sometimes even confounded with psychopathy, despite experts showing that they are separate disorders. ${ }^{156}$ But, this shows that the two disorders are similar enough, that it could be imaginable that psychopathy could have its own place in the DSM. Undoubtedly, further research is required before we can say we know with absolute certainty how the psychopathic mind works and views culpability, interpersonal relations and intention. But, as the evidence described in previous chapters seems to demonstrate, there exists significant enough deviation from non-psychopathic individuals, that separate treatment is warranted.

Critics may argue, however, that psychopathy is not a mental disorder-and that classifying it as such would allow individuals with psychopathic traits a much easier path to the insanity defense. Psychopathy has also been viewed as a 'moral disease $^{\prime 157}$, since the psychopathic individual's moral functioning is most disturbed, which may lend credit to its addition to the DSM, although this claim has not formally been recognized or substantiated. However, whether or not psychopathy can truly be classified as a mental illness, the point stands that the lack of clear and concise classification regarding psychopathy displays how we are lacking the proper

\footnotetext{
${ }^{156}$ Robert D. Hare, "Psychopathy and Antisocial Personality Disorder: A Case of Diagnostic Confusion"

Psychiatric Times, 13, no. 2 (1996); Robert D. Hare, "Psychopathy and the DSM-IV Criteria for Antisocial Personality Disorder", Journal of Abnormal Psychology, 100 no. 3 (1991): 391-8 157 F.A. Whitlock, "A Note on Moral Insanity and Psychopathic Disorders". Psychiatric Bulletin. 6 no.4 (April 1982): 57-59
} 
resources to fully understand psychopathic individuals, especially the unsuccessful type and especially when concerning the legal system. Given the existence of legal framework such as M'Naughten rules and the insanity defense, classification within the DSM would be the easiest route to acquiring the chance at a mitigated attribution of responsibility.

Within the judicial system, the unsuccessful psychopath will suffer from hermeneutical injustice, as the way in which an individual with psychopathic traits forms his intent is not necessarily the same as non-psychopaths. But, because there is only one current picture of intent, individuals with psychopathic traits won't be afforded the opportunity to put their experience to words, or to defend themselves on these grounds. As previously discussed, many traits possessed by psychopaths support the argument that they view crime differently. For example, Robert Hare quotes a psychopath who compares their violent crimes to "the last time you squashed a bug"158. I have argued that based on evidence such as this, that individuals with psychopathic traits do not view personhood the way that most do, such as being empathetic and possessing interpersonal sensitivity toward our peers. This sensitivity affords us the ability to fully appreciate what it means to harm someone else, meaning that we can either expect or predict the gravity of the harm that we will cause, or can afterwards reflect upon the harm that we have caused. But, because the individual with psychopathic traits doesn't have access to the reasons we possess for why not to harm others, they won't view harm in the same

\footnotetext{
158 Robert D. Hare, Without Conscience: The Disturbing World of the Psychopaths Among Us (New York: The Guilford Press, 1993), 30.
} 
way that we do either. Akin to 'squashing a bug', harming someone is easy in the sense that the interpersonal emotional connection isn't there. Additionally, courts have strict guidelines concerning elements of a crime. If it is proven that the offender had both criminal intent and committed an unrestrained or uncoerced criminal act, then that offender is most likely to be found guilty of that crime. Recall, Morse suggested ${ }^{159}$ that although a criminal possesses both elements of a crime, they are not necessarily aware of the effects of the crime in the grander scheme. He draws upon the example of Andrea Yates, a woman who drowned her five children in order to save them from Satan's fiery grasp, and further suggests that individuals with psychopathic traits lack rational capacities when concerning interpersonal sensitivities. Meaning that according to his theory, individuals with psychopathic traits don't have access to any acceptable reasons why not to harm people.

Following this theory, it may be the case that the formation of criminal intent within psychopaths differs from non-psychopaths, and yet, the courts are currently treating them equally. So, akin to Carmita Wood's situation, of being unable to put a word to the concept of sexual harassment, it could be that individuals with psychopathic traits also lack the words to describe how they form intent. Therefore, until we can adequately recognize that the psychopath's nature prohibits him from fully appreciating the crime that he committed, and help them to understand how their minds operate, at least some individuals with psychopathic traits will continue suffering hermeneutical injustice.

159 Stephen J. Morse, “Psychopaths and Criminal Responsibility” Neuroethics 1, no. 3, (2008): 207-8 
Kryastous and Sanati 160 argue that individuals with a borderline personality disorder (BPD) diagnosis consistently suffer from epistemic injustice. They claim that the personality disorder makes it less likely for an individual to be fully responsible for their actions, in the sense that they have awareness, deliberations and decisions for an action. The authors also portray what they describe as an Aristotelian account of responsibility, which calls for two elements. First, the action or trait must have originated in the agent, meaning that there was no external compulsion. Second, the agent must be aware of what their action or trait is doing or bringing about. ${ }^{161}$ So, they argue, in order for an individual to have the capacity for decision and deliberation, they must have control and awareness, something that BPD patients, being known to act without forethought, might not posses. When testing for mens rea, they argue, individuals with BPD are disadvantaged due to the misunderstood way in which the patient forms an intention. This relates back to the argument made by Levy how individuals with psychopathic traits cannot fully intend to harm a person, because they lack a full understanding of personhood. The parallels between BPD and psychopathy are clear; both disorders cause an individual to have difficulty attaching themselves morally to their situation, and both the psychopath and an individual diagnosed with BPD lack the hermeneutic resources within a court of law. The question that remains is why do lawmakers fail to recognize (or even make an attempt to understand) the differences in rational

\footnotetext{
${ }^{160}$ Kyratsous and Sanati, "Epistemic Injustice and Responsibility in Borderline Personality Disorder", 974-980

${ }^{161}$ Kyratsous and Sanati, "Epistemic Injustice and Responsibility in Borderline Personality Disorder", 976
} 
decision-making and intent formation that individuals with psychopathic traits evidently possess? The answer may be found in testimonial injustice.

Individuals with psychopathic traits can also suffer from testimonial injustice within the legal system. Stereotypes and media portrayals have given many people an idea of a Norman Bates-style character in their mind as soon as the word "psychopath" is spoken: crazed, evil and deceitful—the last person you would want to help reduce a prison sentence for. For most people, depictions such as Norman Bates, or Patrick Bateman from American Psycho are the only encounters they've had with psychopathy, and have formed an idea about what they are or how they act from these portrayals. As discussed, psychopathy is considered an aggravating factor for crimes, and can be presented during trial. This could then influence the judge or jury not only to convict and sentence in a certain way, but could also influence how they perceive the offender, in turn giving the offender a deflated credibility. The repugnance that they may feel toward the offender may skew their judgment. There is no question that the average person naturally feels repugnance toward violent crimes. Conversely, because individuals with psychopathic traits do not typically experience remorse, guilt or empathy, they are unlikely to show repugnance toward any criminal or crime, especially the ones that they have committed. This lack of remorse, combined with violent behaviours, causes individuals with psychopathic traits to be characterized as emotionless, evil and serial killers. The deflated judgement that individuals with psychopathic traits may receive could also affect how they are perceived while giving legal testimonybecause individuals with psychopathic traits are known to be deceitful, authorities 
or juries may brush off anything that they have to say, assuming that they are probably lying. Conscience plays an enormous role in the sentencing portion of a trial. It has been demonstrated ${ }^{162}$ that a guilty conscience and displays of remorse allow a criminal likelihood for more lenient sentencing. Recall, mitigating factors for sentencing an offender include guilt or remorse. By contrast, lacking in guilt or remorse will most likely result in higher or maximum sentencing, because they are considered aggravating factors ${ }^{163}$. Thus, an individual with no control over their conscience (or lack thereof) might be significantly disadvantaged in this type of situation; where remorse plays a significant role in sentencing, and they are deficient in remorse.

Individuals with psychopathic traits may also suffer from injustice within the legal system in regards to their knowledge how. However, I view this as a converse to how it was discussed by Hawley. Recall, that Hawley proposed that an individual could be subject to epistemic injustice involving their know-how if they possess the knowledge how to do something, but someone doesn't recognize that they do. The converse could then be reflected as assuming that one possesses knowledge how, when in reality they do not. For individuals with psychopathic traits, the legal system wrongly presumes them to possess knowledge how to respond to moral reasons, when they do not have access to this know-how. In line with Morse's ${ }^{164}$ argument that individuals with psychopathic traits lack rational capacities in

\footnotetext{
162 Rocksheng Zhong, Madelon Baranoski, Neal Feigenson, Larry Davidson, Alec Buchanan and Howard V. Zonana, "So You're Sorry? The Role of Remorse in Criminal Law", Journal of the American Academy of Psychiatry and the Law, 42, no. 1, (March 2014), 39-48

163 "Aggravating and Mitigating Factors", Criminal Law, Justia, Accessed July 24, 2019, https://www.justia.com/criminal/aggravating-mitigating-factors/

164 Morse, Psychopaths and Criminal Responsibility, 208
} 
regards to concern for others and interpersonal sensitivities, one could say that individuals with psychopathic traits lack the specific know-how associated with both of these abilities. In other words, individuals with psychopathic traits lack the necessary practical knowledge involved with care and concern for others. So, when they find themselves in legal trouble, the implication is that they are being prosecuted for something that necessitates practical knowledge that that do not possess. Thus, the psychopathic person's inability to access or gain the know-how puts them at a significant legal disadvantage considering that lacking guilt, remorse or concern for others may increase his prison sentence.

In this chapter, I have demonstrated several ways that individuals with psychopathic traits can suffer from epistemic injustice within the legal system. Notwithstanding the severity of the crimes that they commit, individuals with psychopathic traits are still supposed to be equal in the eyes of the law, and if it can be proven concretely that there is a difference in how they perceive these crimes, it's the duty of lawmakers to take the necessary steps to handle them appropriately. 


\section{Chapter IV}

\section{Unification of Ideas}

Given what we have discussed in the previous chapters, it can be agreed that to some degree, individuals with psychopathic traits suffer from a deficiency in their moral reasoning. This affects their rational capacities in both concern for others and interpersonal sensitivities. While skeptics and critics may disagree about how severe or debilitating this deficiency is, weak reactive attitudes and lack of remorse are both key traits seen on the PCL-R, as well as in many unsuccessful psychopaths.

Some psychopaths exist who do not necessarily score the same as other psychopaths on the diagnostic tool, and this is reflected in their ability to avoid legal trouble, and to generally be fully-functioning members of society-so much so that they can achieve, and keep, high-paying jobs, such as CEO, lawyer or surgeon. This key difference lies in how individuals with psychopathic traits can be subcategorized into "type 1 or type 2", or unsuccessful or successful psychopaths. As such, the discussion has, and will continue to be concerning the unsuccessful type of psychopaths, the ones that more often find themselves in legal trouble. But, while most of my discussion is directed toward unsuccessful psychopaths, it is important to note that there are still several instances, such as prejudiced judgements, that will apply to successful psychopaths as well. 
Evidence such as brain scans ${ }^{165}$, physiological testing ${ }^{166}$ and psychiatric interviews points to individuals with psychopathic traits having different reactive attitudes or responses to sad, frightening or disturbing images, or flat out admitting indifference toward another's livelihood. What many psychologists, philosophers and legal theorists have concluded from this is that individuals with psychopathic traits have a deficiency in empathy, which suggests additionally, a lacking in morality. Empathy and morality are intrinsically tied together, thus it is hard to imagine having one without the other. When we think of morally praiseworthy or virtuous acts, or more specifically, actors, we judge their characters to be equally moral and virtuous. Empathetic actors, or those who are capable of feeling a deep appreciation for the pain that others feel, are judged similarly. Their capacity to perceive the pain that another feels also guides both their judgement and their moral compass. For example, after someone has worked a retail job and has been mistreated by customers, they then are more aware of how they treat other people working in the service industry. In other words, people's treatment of others is dependent on their ability to connect with others. Conversely, lacking empathy, as seen in individuals with psychopathic traits, is linked with antisocial behaviours and inability to connect with others. Without the driving force of empathy behind them, it's unsurprising that individuals with psychopathic traits are morally deficient.

\footnotetext{
165 Elizabeth Shaw "Psychopathy, Moral Understanding and Criminal Responsibility", European Journal of Current Legal Issues, 22, no. 2 (2016) 11

${ }^{166}$ Shaw, Psychopathy, Moral Understanding and Criminal Responsibility, 11
} 


\section{Moral Deficiency}

If we opt to argue charitably and grant that individuals with psychopathic traits indeed possess a moral deficiency, the question of what exactly this entails still remains. Recall in an earlier chapter we defined the differences epistemologists draw between types of knowledge. First, one can posses knowledge that, or propositional knowledge-which refers to when we have knowledge about things. For example, I know that driving a manual transmission car entails not only using the gas and brakes, but also a manual gear shifter and clutch. Secondly, one can possess knowledge how, or practical knowledge-which refers to the knowledge someone possesses when they know how to do something. If I have knowledge how to drive a manual transmission car as opposed to only propositional knowledge, I will possess the knowledge how to actually switch gears, apply my foot on the clutch and properly drive the car. Third, we discussed knowledge why, which refers to the more strict understanding of why something is what it is. Take the car example, to possess knowledge why of some sort on manual transmission cars, I could say for example, that I know why (mechanically) you should avoid popping your clutch. Some critics ${ }^{167}$ argue against psychopaths' mitigated responsibility by claiming that the individual with psychopathic traits is aware of society's morals and expectations and therefore are not deficient of morality; instead they simply ignore the rules. The types of knowledge discussed above provide an answer to why this may be. When it is observed that an individual with psychopathic traits knows

167 Heidi L. Maibom, “The Mad, the Bad and the Psychopath”, Neuroethics, 1 no. 3 (2008): 167-184 
about the social expectations that we have set for ourselves, it seems most likely that said observation is an instance of possessing propositional knowledge on morality. He knows, for example, that it is considered wrong to steal from someone, both because it is illegal but also because it is considered by society to be intrinsically wrong. However, the psychopathic individual does not possess the relevant knowledge how related to both empathy and morality. In this sense, it means that individuals with psychopathic traits cannot access the practical knowhow involved with empathizing and interpersonal sensitivities.

Similarly, psychopath's deficiencies will also keep them from being able to access relevant knowledge why they ought to avoid causing harm to others. Although they possess the superficial knowledge why to avoid hurting people, which is similar to his propositional knowledge-that they should avoid it because it is illegal and society has set the demands that it is morally impermissible, he lacks the capacity to grasp the deeper understanding of why that it is morally impermissible, and why, aside from rules, they ought to avoid causing people harm. Although reasons why can be explained to them, without the capacities to understand these reasons, the individual with psychopathic traits will not gain any genuine knowledge why, and will simply be gaining the ability to recite the reasons back to us.

When young children are taught why it is wrong to hit a classmate, presumably they did not previously access or possess the relevant knowledge why they should not do this. Typically, once they learn why this is wrong, they'll avoid this behaviour further, not because it is illegal, but because they have grasped that 
said behaviour is not nice, or it hurt their classmate's feelings. While most people can reflect on why we ought not to harm others using moral reasons and come to a solid understanding, individuals with psychopathic traits are not able to come to the normal conclusions.

Lacking interpersonal sensitivity also means that psychopaths are unlikely to view personhood in the same way that non-psychopaths do. This is not to say that individuals with psychopathic traits are non-persons, but instead that the way they relate to others is not that same as non-psychopathic individuals. Rather, a feature unique to individuals with the capacity for empathy is the ability to relate to other persons in a very specific way. The reason many have decided harm on a human being is morally worse than harm on a non-human animal is because of our depth of understanding of personhood; we know, as persons, how it feels to be harmed, or feel hopeful, or happy, or sad or any other range of emotions. Moreover, we have the ability to communicate these feelings with one another and recognize what someone is feeling. Because of this understanding, we have an appreciation for others-we feel sad when something bad happens to them or happy when something good happens. Non-human animals on the other hand, with, perhaps, the exception of our pets, lack the ability to communicate and create a connection with us in a way that is 'uniquely human'. As a result, the connection and more importantly, the empathy that we feel for them fails to reach what we feel for our fellow humans. I argue that individuals with psychopathic traits, in being morally deficient and lacking empathy, lack the aforementioned picture of personhood. That 
is, they cannot connect with other people on a deeper level how most people can; the idea of feeling hopeful or sad for another human is foreign to them.

Another effect that arises from psychopath's moral deficiency is how they form intent differently that non-psychopaths do. There are two reasons to believe this. First, per Neil Levy ${ }^{168}$ individuals with psychopathic traits appear to have issues with mental time travel ${ }^{169}$ — which refers to episodic memory. According to Levy, individuals with psychopathic traits struggle with combining past, present and future into a cohesive whole. Episodic memory and prospection, the ability to see oneself in past event or to project oneself into the future, are key factors in mental time travel, and individuals with psychopathic traits, according to Levy, struggle with both. And further, they also show difficulties in emotional recall. Because they are "stuck in the present"170, he argues, they cannot see themselves persisting through time, with plans and projects, which personhood entails. This lack of persistence, personhood and linear personal timeline thus demonstrates how their deficiencies cause them to be unable to intend to harm another person. In other words, a psychopathic person's struggle lies in their difficulty foreseeing how actions lead to consequences. This is important in the formation of intent, as fully understanding consequences of actions is required for one to properly form a criminal intention. For example, an individual diagnosed with schizophrenia would likely not be considered to have formed a proper intent had they committed a crime during a severe auditory hallucination, when they could not focus on the

\footnotetext{
168 Neil Levy, "Psychopaths and Blame: The Argument from Content" Philosophical Psychology, 27 no. 3 (2014): 351-367

169 Levy, Psychopaths and Blame, 360

170 Levy, Psychopaths and Blame, 361
} 
moral/legal consequences of their actions. Second, because psychopaths cannot relate to persons in the same way that non-psychopaths can, it cannot be said that they form intent in the same way. To fully intend to cause harm to a person, one must fully understand the harm that they will cause. If an individual with psychopathic traits does not understand what it means to be a person, they equally cannot understand what it means to harm a person, or how a person feels when they are harmed. Of course, people with psychopathic traits can intend to cause harm in the very basic sense that I could intend to throw a plastic six-pack ring over the side of my boat, while not knowing the greater effects that that plastic could have on the oceanic ecosystem. While I formed the intention to throw my garbage away, I did not have a greater understanding of the effects that my actions could set forth, even if I had superficial knowledge that littering is bad. Similarly, without a fuller understanding of personhood, individuals with psychopathic traits can also only form a very simple intention.

\section{Epistemic Injustice}

Recall, epistemic injustice refers to a wrong done to someone "specifically in their capacity as a knower"171. Fricker describes that an individual can suffer from Testimonial or hermeneutical Injustice. Testimonial injustice occurs when identity prejudice cause an individual to give deflated credibility to another. Hermeneutical injustice, Fricker's other type of epistemic injustice, occurs when a concept is not yet

${ }^{171}$ Miranda Fricker, Epistemic Injustice: Power and the Ethics of Knowing Oxford: Oxford University Press, 2007), 1. 
understood or accepted in mainstream society. As a result, and individual will not have the proper hermeneutic resources required to help them navigate and understand their issues.

Currently, in the justice system, in order for someone to be considered guilty (or at least applicable to be tried) of a crime, they must have two key elements present. The individual must have mens rea-criminal intent and actus reus-a criminal act. So, if it is proven that the accused intended to commit the crime, meaning that they weren't forced in any way to commit it, and it truly was them that committed the crime, then they can be tried and/or found guilty. If a psychopathic person commits a crime that has not been done out of coercion or any other forcible method, then they will be treated as having mens rea in the same way that nonpsychopaths do.

If we grant that people with psychopathic traits indeed form their criminal intentions in a different manner than non-psychopaths, various injustice issues with the legal system then arise. Broadly, it shows that they are not being treated fairly because they operate differently. This brings about injustice in how they are treated in trials, and also in their capacity as a knower, because society has yet to have widespread understanding of how they form intent. As it currently stands, the legal system makes no attempt to recognize, acknowledge or investigate potential differences in how individuals with psychopathic traits form their intentionsmeaning that psychopaths currently do not have any resources to navigate their situations; even the best lawyer would not be able to make a case for them based on their intent formation. And, without the collective social understanding of the 
individual with psychopathic traits' grasp, or lack thereof, on knowledge surrounding moral understanding and concern for others, the psychopathic person could be unable to make sense of their behaviour. Without the proper resources that recognize the differences between psychopaths and non-psychopaths, legal issues that a person with psychopathic traits may suffer will lead to their suffering of epistemic injustice. The legal system has accepted and made many changes for individuals with mental disorders. It recognizes that certain illnesses preclude offenders for being held responsible for their actions. Therefore, similar recognition or mitigation of responsibility for individuals with psychopathic traits should not be too difficult to conceptualize.

Regarding responsibility, Daphne Brandenburg offers an insightful reconciliation between Strawsonian blaming attitudes-that we ought not to blame a person for their actions when their abilities to meet our demands are severely impaired ${ }^{172}$-while also holding patients responsible for their actions. In essence, although we do not use blaming attitudes toward a patient for doing something wrong (i.e. saying "you have ruined this for me!), but we do hold them accountable for their actions (i.e. "this is not acceptable behaviour, how are you going to fix this"). This model could offer some insight as to how to treat psychopathic offenders. Because they form their intent differently, we ought not completely blame them for their actions, but we can still hold them accountable for their behaviours because they possess relevant propositional knowledge.

\footnotetext{
172 Daphne Brandenburg, "The Nurturing Stance: Making Sense of Responsibility without Blame",
} Pacific Philosophical Quarterly, 99 no. 1 (2017): 7 


\section{What Needs to Change?}

In order for injustices to no longer persist for individuals with psychopathic traits, I propose that we need to see several changes in the legal system in the both treatment and handling of psychopathic offenders and the legal structure more generally. First and foremost, the way that individuals with psychopathic traits are treated throughout the legal system would have to change. For people with psychopathic traits, I think that a less rigid test for mens rea should be in place for those that have scores above 30 on the PCL-R. This could mean revisiting intent, or perhaps throwing it away for them altogether. Of course, more research would need to take place to have a firm grasp on the formation of their intent. This would likely lead to a case-by case structure, where some cases will find individuals with psychopathic traits having "enough" understanding of morality and personhood to have formed a proper intent, where there are others who do not pass the test for having formed a criminal intent. The treatment of individuals with psychopathic traits could be structured more akin to the treatment of the mentally ill, where they would be civilly confined in a type of treatment facility. While there is little to no evidence that psychopathy is something that can be "cured", some research suggests ${ }^{173}$ the possibility of psychopathy having genetic markers. Further research into the issue would be required, but depending on the findings, civil confinement could go one of two ways. However unlikely, if it were found that we could cure or

\footnotetext{
173 Daniel M. Blonigen, Brian M. Hicks, Robert F. Krueger, Christopher J. Patrick, and William Iacono. "Psychopathic Personality Traits: Heritability and Genetic Overlap with Internalizing and Externalizing Psychopathology" Psychological Medicine, 35 no. 5, (2005): 637-48.
} 
partially cure individuals with psychopathic traits-perhaps getting them from unsuccessful to successful, or even having them gain the ability to understand morality and personhood, then treatment facilities would mainly focus on the rehabilitation of the offenders, to help make them into productive members of society. This could include regular meetings with clinical professionals, and responsibilities within the facility, like jobs and duties. It could also be a place to allow the offenders to learn (or relearn) how to properly socialize and make connections with others. They could be taught about the consequences of their actions and also how to control their impulses and need for stimulation. If the psychopathic individual could be reformed, then it could be possible for them to be released afterwards. If psychopathic people cannot be cured-meaning that psychopathy is a condition one lives with for their entire life, civil confinement may need to remain permanent, depending on the crime committed and number of offenses the offender has had. This does not mean to abandon all hope of reform with the psychopath; there could still be programs to try to help individuals with psychopathic traits control their impulsivity and teach them about accountability and responsibility for their actions, in Brandenburg's sense. Additionally, living with other offenders in the facility could serve as an attempt to teach them to live civilly with other people. Even if they never gain access to knowledge why and how on morality, this does not mean that they will not learn to follow them based on their propositional knowledge and proper rehabilitation.

Another, simpler, change that could take place to help individuals with psychopathic traits is to recognize it as a mental disease. Although currently, is it not 
recognized as such, Nadelhoffer and Sinnott-Armstrong ${ }^{174}$ offer a compelling account for why this should be accepted. Although individuals can be diagnosed with psychopathy using the PCL-R, the authors admit that an "arbitrary list of symptoms is not a disease" 175 .

They outline factors which help support that psychopathy is a mental disease. First, cognitive psychologists found that individuals with psychopathic traits:

1. Often act in their own worst interest

2. Exhibit cognitive-perceptual deficits in the recognition of emotions in others' faces and voices

3. Have deficits in attention, have exaggerated views of their own capabilities

4. Exhibit shortcomings in the so-called gambling task (a psychological task used to study emotion and cognition)

5. Have deficits in response reversal (the inhibition of previously rewarded responses that are now punished)

6. Fail to pass the Moral-Conventional Distinction Task ${ }^{176}$

Next, they showed that individuals with psychopathic traits also possess functional neural deficits:

\footnotetext{
174 Thomas Nadelhoffer and Walter Sinnott-Armstrong, "Is Psychopathy a Mental Disease?" in Neuroscience and Legal Responsibility, ed. Nicole A. Vincent (New York: Oxford University Press, 2013), 229-56

175 Nadelhoffer and Sinnott-Armstrong, "Is Psychopathy a Mental Disease?" 233

176 Nadelhoffer and Sinnott-Armstrong, "Is Psychopathy a Mental Disease?" 233
} 
1. Psychopaths display reduced amygdala and vmPFC activity during aversive conditioning tasks

2. They show impairment in passive avoidance and learning tasks and differential reward-punishment tasks associated with amygdala activity

3. Reduced amygdala activation during emotional memory

4. They show reduced amygdala activation in the anterior and posterior cingulate gyri, left interior frontal gyrus, amygdala and ventral striatum when encoding, rehearsing and recognizing negatively valenced words

5. Reduced activity in the ventromedial prefrontal cortex, anterior temporal cortex, and amygdala when rating severity of moral violation in images ${ }^{177}$

Finally, they showed what researchers have found about the neurochemistry of individuals with psychopathic traits:

1. The neurotransmitter noradrenaline plays an important role in the deficits associated with psychopathy

2. Administering noradrenaline antagonists reduces the impact of aversive cues when making decisions

3. Amygdala activity in response to emotional stimuli is reduced by administration of noradrenaline antagonist

177 Nadelhoffer and Sinnott-Armstrong, "Is Psychopathy a Mental Disease?" 234 
4. Differences can be found in psychopathic and non-psychopathic offenders with respect to cortisol function. ${ }^{178}$

Given the bulk of these symptoms that exist beyond the PCL-R, that all individuals with psychopathic traits experience, along with psychopathy being both affective (as opposed to largely behavioural) and predictive of future violence, Nadelhoffer and Sinnott-Armstrong come to the conclusion that psychopathy should be considered a mental disorder. They also consider several theories on mental disorders, showing how psychopathy could be argued as a disorder under any of them. Rather than creating new legislature for individuals with psychopathic traits, if the disorder were recognized as a mental disease, then individuals with psychopathic traits would simply have the option to use an insanity plea. As with other mental diseases, the individual would have to be assessed as to whether of not they are able to appreciate the wrongfulness of their act, and if they are not, they would be found not guilty. In theory, this would eliminate any injustices that they experience due to their identity, and presumably they would have more resources to better understand they way that they operate, and in what capacity it differs from non-psychopathic individuals.

178 Nadelhoffer and Sinnott-Armstrong, "Is Psychopathy a Mental Disease?" 234 


\section{Worries and Challenges}

There are a few worries or challenges that will undoubtedly arise from my suggestions. In this section, I will discuss what I believe to be some of the main challenges, and my responses that follow.

First, one might argue that if we begin to make exceptions for individuals with psychopathic traits, who have plainly committed bad actions, that an endless regress of defying the legal system will unfold. Those who favour this argument may also question where do we draw the line? If we stop punishing more and more offenders who have committed crimes, then we are, in a sense, throwing away what they see as one of the main objectives of the justice system, which is punishing criminals for committing illegal acts.

I believe the fault in this objection lies in the assumption that the justice system is in place for punishment or retribution of those who have committed illegal acts. Of course, there needs to be a system in place which holds persons who do not abide by the laws set forth by the nation. That being said, pure punishment, or "an eye for an eye" attitudes for crimes is dated and has proven ${ }^{179}$ to not be the most effective way to house criminals, as far as reducing the rate of recidivism in convicts.

\footnotetext{
${ }^{179}$ Many studies, books, textbooks, papers have shown that rehabilitation reduces recidivism in prisoners. For example: Danielle S. Nagin, Alex R. Piquero, Elizabeth S. Scott, and Laurence Steinberg, "Public Preferences for Rehabilitation versus Incarceration of Juvenile Offenders: Evidence from a Contingent Valuation Survey", Criminology and Public Policy, 5 no. 4, (2006): 627-651 Allan I. Abrams and Larry M. Siegel, "The Transcendental Meditation Program and Rehabilitation At Folsom State Prison: A Cross-Validation Study" Correctional Psychologist, 5 no. 1, (March 1978): 3-20 Earl O. Strimple "A History of Prison Inmate-Animal Interaction Programs." American Behavioral Scientist 47, no. 1 (September 2003): 70-78.
} 
Ultimately, the aim should be to have as little people reoffending after their release as possible. The system that has shown to work best for this aim is to rehabilitate our offenders in hopes that they learn and grow from their errors, and understand why to not fall down the path of crime again. So yes, in a sense, we are moving away from the archaic tradition of punishing our convicts, but most developed countries have also moved away from torture and capital punishment. It's the lawmakers responsibility to take the best course of action to reform convicts-not only for the safety and wellbeing of the general public, but also for the offenders, so they can have hope for a second chance and to live outside of bars. Similarly with psychopaths, our best hope is to try to rehabilitate them as best possible, both for us and for them. A final point, although rehabilitation may not be strictly "punishment" in a strict, vengeance, sense, civil confinement does not equate to freedom and therefore still is punishment in a looser sense.

A second worry that critics may have is concerning the psychopathic individual's autonomy, or what I call a Kantian objection. According to this objection, mitigating the psychopathic individual's responsibility treats them paternalistically and thus brings about the implication that they're lesser than other people because of their condition. This objection also shares similar concerns with the previous objection; because individuals with psychopathic traits have criminal intent, treating them in the same way as the mentally ill when they are not mentally ill is comparable to treating them like children. As a Kantian would say, no rational adult, including individuals with psychopathic traits, ought to be treated that way, given the demands of equality. Mitigating the psychopathic individual's blame 
lessens their individual worth—essentially, each individual must be kept accountable for their actions in order to be respected as an individual. Regardless of their moral deficiencies, we must hold them accountable for their actions.

In response to this worry, I would first argue, as Morse ${ }^{180}$ does, that individuals with psychopathic traits lack rational capacities when it comes to issues of morality and interpersonal sensitivities. This in itself seems a sufficient reply, as individuals with psychopathic traits will not fall within the parameters of "all rational adults". But further, while it is true that the treatment would perhaps lessen the individual value of the person with psychopathy, the alternative involves far more injustice, being that if a person is unable to fully form a criminal intention, it is not just to punish them in the same manner than an individual who has fully formed an intention. An example may make this clearer: Say man A is an undiagnosed schizophrenic, and begins to experience auditory hallucinations, which eventually convince him that his wife is not in fact a human, but a demon, and that he needs to kill her-which he does. Suppose man B wants to be with a younger, prettier woman and doesn't want to split half of his belongings with his current wife, so he slips her some sleeping pills and shoots her while she is sleeping. There is no way that man A and man B can be considered equally guilty for their crimes; while man A would require treatment from healthcare professionals and medications, man B would require nothing more than his right to a fair trial. Given the circumstances of man A's illness, he could not be treated equally. To treat both men equally when their motivations and moral content were entirely different is a complete

${ }^{180}$ Stephen J. Morse, "Psychopaths and Criminal Responsibility" Neuroethics 1, no. 3, (2008): 205-212 
mistreatment of both men, if we truly wish to meet the demands of equality. Further, proponents of this objection must consider that in order to meet said demands for equality, holding individuals with psychopathic traits responsible for their actions while mitigating their blame is in fact promoting their autonomy, because this way they may learn to control their impulses and take accountability for their actions.

Finally, one might argue that there is not enough evidence to prove that individuals with psychopathic traits lack any real deficiency to warrant mitigated blame. We have opted to argue charitably and assume, based on evidence, findings and interviews, that there is a real issue with how unsuccessful individuals with psychopathic traits relate to, understand and know about other people and morality and empathy more generally. Suppose someone does not want to argue charitably, and instead believes that it is simpler to just assume that individuals with psychopathic traits are bad people ${ }^{181}$.

I will say first, if someone wants to deny that individuals with psychopathic traits lack moral rational capacities and lack capacities to effectively relate to persons, that there is indeed a lack of concrete proof at this time. I have argued that given traits on the PCL-R, physiological testing, brain scans, interviews and expert opinion that it seems most likely that individuals with psychopathic traits suffer from the above mentioned deficiencies, so much so that their ability to form intent and have a cohesive understanding of the effects of their actions is compromised. With this informed assumption, I have argued for why I believe individuals with

${ }^{181}$ Maibom, The Bad, the Mad and the Psychopath" 167-184 
psychopathic traits suffer epistemic injustice when they run into trouble with the law. However unlikely I've come to think them being "just plain bad" is, this possibility does still exist so long as we have yet to find concrete evidence. That being said, lack of concrete evidence is, of course, not a good reason to deny the existence of something. Historically, hyperactive and inattentive students were simply considered bad children, and that the students only had to work harder to pay attention. Of course now, a student can be diagnosed with attention deficit hyperactivity disorder; simply because a diagnosis has yet to exist, does not warrant denial of the related disorder. Human behaviour has all shown to have a reason behind its manifestation. Assuming any human behaviour is random or without explanation is hasty and an oversimplification of the brain's complexity. Some of the most extreme deviant behaviours, such as pedophilia, have begun to show cases where the individual is not necessarily "simply a bad person". A 40-year-old man who had developed pedophilia as well as other strong deviant sexual urges was later found to have had a brain tumour ${ }^{182}$. Further, it seems simpler to assume that all behaviour has a reason or motivation for that behaviour. If some people simply act out badly, even that must have a motivator. But importantly, what is even meant by "bad" behaviour? Badness is merely the converse of goodness. So, what is goodness in people? Goodness, or praiseworthiness can count as caring for others, acting selflessly, having concern for others, caring for others; having an

182 Charles Choi, "Brain tumour causes uncontrollable paedophilia," News Scientist, October 21, 2002. https://www.newscientist.com/article/dn2943-brain-tumour-causes-uncontrollable-paedophilia/; Gabriel Tanasescu, "The Causal Link between Functional Disorder of the Orbitofrontal Cortex, Disorder of Moral Reasoning and Aggressive Sexual Behavior" Rais Journal for Social Sciences, 3 no. 1 (2019): 99-113 
interpersonal sensitivity, empathy and respect for others can sum up what we believe goodness to be. So badness, on the other hand, could just be called the absence of these qualities: not caring for others, acting selfishly, lacking concern for others, not caring for others and lacking interpersonal sensitivity. Recalling the earlier reply, it seems unlikely that individuals with psychopathic traits act in this way for no reason or that this behaviour is unexplainable. A much more likely reason for their lacking goodness is that they cannot access the reasons why or how to act good, like non-psychopaths do, regardless if they have access the knowledge that other people act in such a way.

\section{Looking Further}

A final question to ask is whether this discussion on psychopathy and epistemic injustice can be applied elsewhere, and I believe the answer is yes, it can. There are without a doubt other individuals who have issues surrounding the formation of intent that pass the test for mens rea and are therefore seen to be fit to stand trial. Other personality disorders for example, are what first come to mind. I'll discuss just two, which both possess antisocial behaviours and blunted empathy. Antisocial personality disorder (ASPD) is similar to psychopathy's Factor 2 traits, which deals with their anti-social behaviours. According to the DSM-5, ASPD is characterized by the following: 


\section{A. Significant impairments in personality functioning manifest by:}

\section{Impairments in self-functioning (a or b):}

a) Identity: Ego-centrism; self-esteem derived from personal gain, power, or pleasure.

b) Self-direction: Goal-setting based on personal gratification; absence of prosocial internal standards associated with failure to conform to lawful or culturally normative ethical behavior.

AND

2. Impairments in interpersonal functioning (a or b):

a) Empathy: Lack of concern for feelings, needs, or suffering of others; lack of remorse after hurting or mistreating another.

b) Intimacy: Incapacity for mutually intimate relationships, as exploitation is a primary means of relating to others, including by deceit and coercion; use of dominance or intimidation to control others.

\section{B. Pathological personality traits in the following domains:}

\section{Antagonism, characterized by:}

a. Manipulativeness: Frequent use of subterfuge to influence or control others; use of seduction, charm, glibness, or ingratiation to achieve one's ends.

b. Deceitfulness: Dishonesty and fraudulence; misrepresentation of self; embellishment or fabrication when relating events.

c. Callousness: Lack of concern for feelings or problems of others; lack of guilt or remorse about the negative or harmful effects of one's actions on others; aggression; sadism.

d. Hostility: Persistent or frequent angry feelings; anger or irritability in response to minor slights and insults; mean, nasty, or vengeful behavior.

\section{Disinhibition, characterized by:}

a. Irresponsibility: Disregard for - and failure to honor - financial and other obligations or commitments; lack of respect for - and lack of follow through on - agreements and promises.

b. Impulsivity: Acting on the spur of the moment in response to immediate stimuli; acting on a momentary basis without a plan or consideration of outcomes; difficulty establishing and following 
plans.

c. Risk taking: Engagement in dangerous, risky, and potentially self-damaging activities, unnecessarily and without regard for consequences; boredom proneness and thoughtless initiation of activities to counter boredom; lack of concern for one's limitations and denial of the reality of personal danger

C. The impairments in personality functioning and the individual's personality trait expression are relatively stable across time and consistent across situations.

D. The impairments in personality functioning and the individual's personality trait expression are not better understood as normative for the individual's developmental stage or sociocultural environment.

E. The impairments in personality functioning and the individual's personality trait expression are not solely due to the direct physiological effects of a substance (e.g., a drug of abuse, medication) or a general medical condition (e.g., severe head trauma).

F. The individual is at least age 18 years.

Many of the qualities that I have argued that deem individuals with psychopathic traits worthy of a mitigated attribution of responsibility could also apply to those with ASPD. There is overlap between the two, having a great deal of traits shared. One key difference used to lie in the psychopathic lack of empathy and shallow affect, with ASPD not sharing this trait, however an updated version of the DSM has since included lack of empathy for ASPD persons. ${ }^{183}$. Given the similarities between the two conditions, it seems likely that individuals with ASPD form intent differently than individuals without ASPD. If they too lack capacities in seeing events as a

\footnotetext{
183 James R. P. Ogloff, Rachel E. Campbell, and Stephane M. Shepherd, "Disentangling Psychopathy from Antisocial Personality Disorder: An Australian Analysis", Journal of Forensic Psychology Practice, 16 no. 3 (2016): 198-215
} 
cohesive whole, or more generally, the ability to understand personhood, there is a possibility that ASPD causes a difference in the formation of intent, which means that many more inmates could have suffered epistemic injustice as well.

Individuals with borderline personality disorder (BPD) are also often entangled with the law. BPD is another personality disorder that is characterized by an unstable sense of self or unstable interpersonal relationships. The DSM-5 criteria for BPD are as follows:

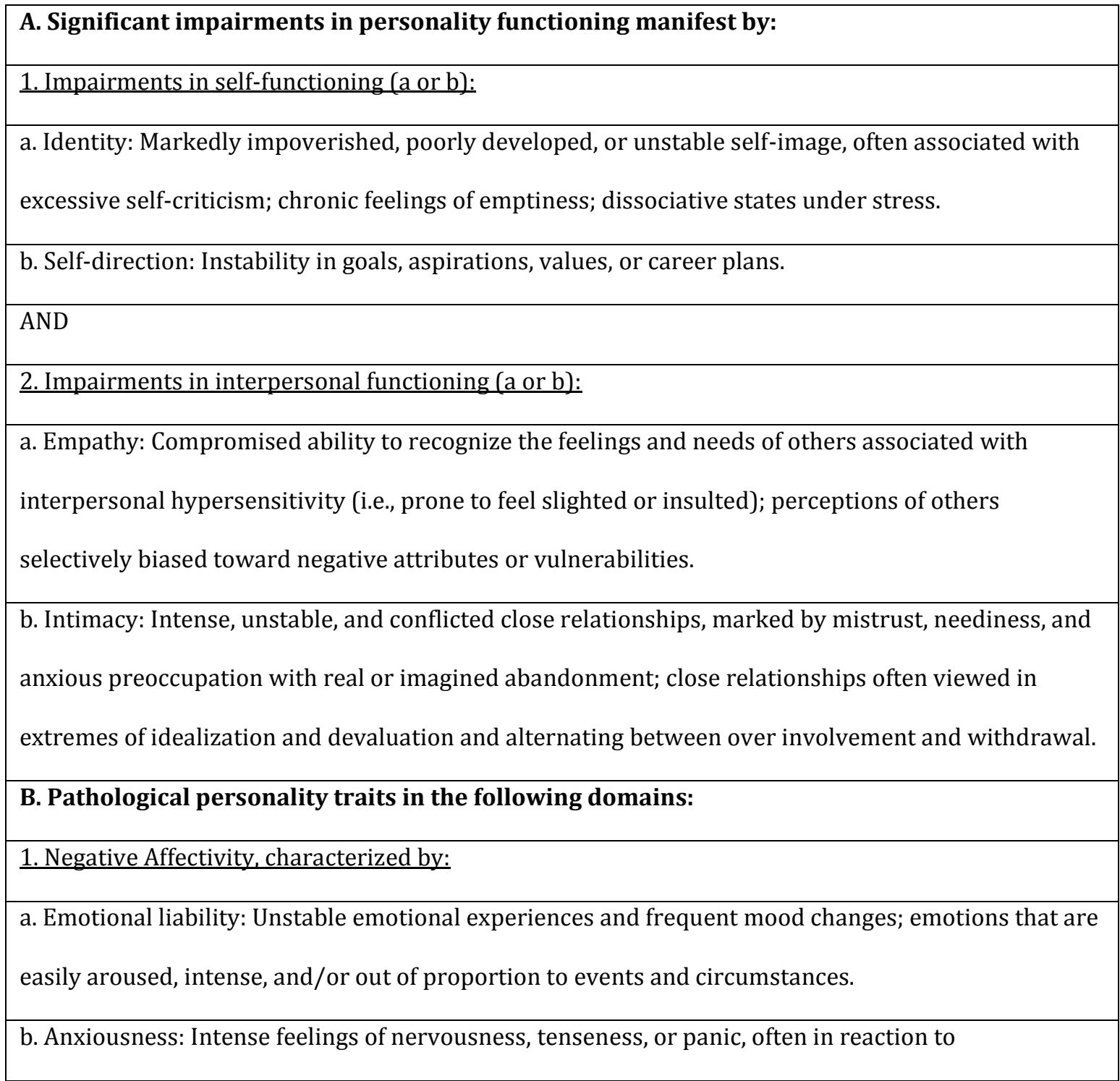




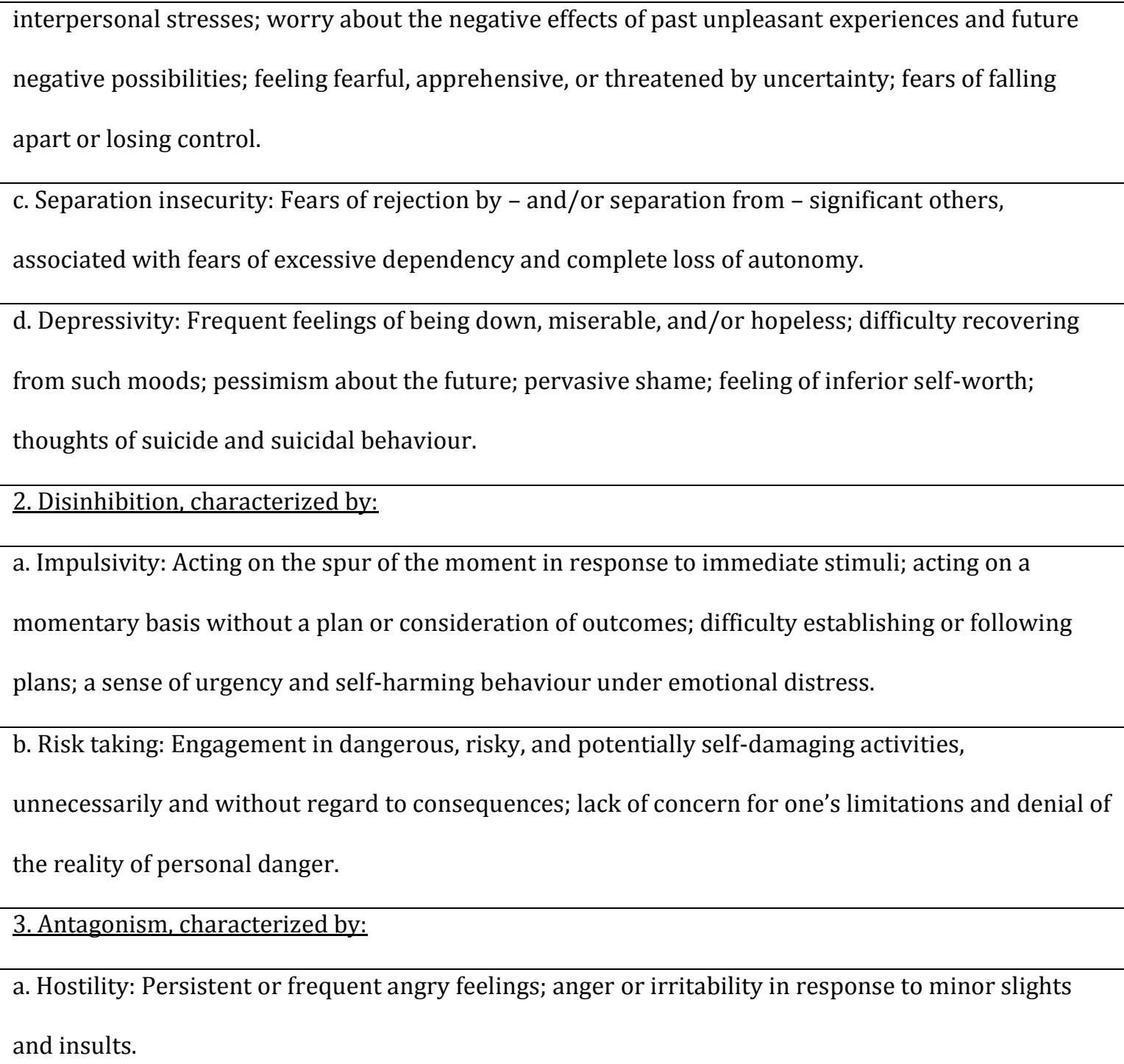

a. Hostility: Persistent or frequent angry feelings; anger or irritability in response to minor slights and insults.

\section{The impairments in personality functioning and the individual's personality trait}

expression are relatively stable across time and consistent across situations.

\section{The impairments in personality functioning and the individual's personality trait} expression are not better understood as normative for the individual's developmental stage or socio-cultural environment.

\section{E. The impairments in personality functioning and the individual's personality trait} expression are not solely due to the direct physiological effects of a substance (e.g., a drug of 
abuse, medication) or a general medical condition (e.g., severe head trauma)

Kryastous and Sanati ${ }^{184}$ have made the argument that individuals with BPD suffer from epistemic injustice. They also put forth the argument that the way in which they form intent is misunderstood, even though they are held to the same standards as those without BPD. Intent formation aside, patients with BPD appear to have even greater issues than individuals with psychopathic traits when concerning rational capacities, given the addition of the unstable sense of self it would seem that an individual with BPD would have even greater difficulty making sense of personhood. Because they lack many functions in their own self-image, attempting to relate to other persons would be even more difficult given they may not have the ability to relate back to themselves. To truly empathize with someone, we must be able to imagine or relate our own pain or emotions to the person's situation. But, their pervasive self-criticism, depressiveness and lack of self-worth would likely make this more difficult to relate back to. Given they also possess issues with interpersonal relationships and impulse control, individuals with BDP may also be applicable for Levy's Mental Time Travel argument. Their lack of long-term plans and impulsiveness, along with emotional instability make them good candidates for being unable to see their actions as a cohesive whole. Perhaps even more so than individuals with psychopathic traits, do individuals with BPD require attention from

\footnotetext{
${ }^{184}$ Michalis Kyratsous and Abdi Sanati, "Epistemic injustice and responsibility in borderline personality disorder", Journal of Evaluation in Clinical Practice, 23 (2017) 974-980
} 
lawmakers. In a 2010 study, 185 researchers found in a sample that $44 \%$ of the subjects were considered to have BDP (or 31\% using a more conservative score) compared to $15 \%$ of the subjects being psychopathic. As Kryastous and Sanati have suggested, it seems highly likely that individuals with BPD suffer epistemic injustice. And similarly with individuals with psychopathic traits, regular prison sentences are not the solution for these individuals. They too would benefit from a rehabilitationfocused treatment that could hopefully work toward the betterment of the individual.

Finally, I think these arguments could say a few things about the legal system in general. First, rather than a case-by-case method, where more and more individuals are shown to suffer from Epistemic Injustice, it would be more desirable to simply revisit the elements of crime and treat intent differently for each offender. Rather than simply asking if they intended to commit the crime, we need to take a deeper look first on how that individual forms their intent. Do they, for example, empathize with people, do they take responsibility for actions in the long-term, and do they view realistic consequences for their actions? All of these questions would be important first steps to ask before considering whether or not an offender truly intended to commit a crime.

\footnotetext{
185 Courtney Conn, Rebecca Warden, Jeffrey Stuewig, Elysha H. Kim, Laura Harty, Mark Hastings, and June P. Tangney. "Borderline Personality Disorder Among Jail Inmates: How Common and How Distinct?" Corrections Compendium, 35 no. 4 (2010): 6-13
} 


\section{Conclusion}

In this thesis, I have shared several accounts, which point to why individuals with psychopathic traits are deserving of a mitigated attribution of responsibility. Holding them criminally responsible for their actions, along with many ways that they are treated within the legal system, leads to various forms of injustice. I have recounted how and why many authors argue for individuals with psychopathic traits to not be held fully responsible for their actions, due to their personalities, rational capacities, neurochemistry and more. Additionally, I have offered an unexplored aspect within the literature on psychopathy, epistemic injustice, and explained why individuals with psychopathic traits can and will be subject to it when they inevitably meet trouble with the law. Hopefully, research will progress the public's understanding of psychopathy, so that one day the matrix of their injustice can cease to exist. 


\section{References}

Abrams, Allan I., and Siegel, Larry M., "The Transcendental Meditation Program and Rehabilitation At Folsom State Prison: A Cross-Validation Study" Correctional Psychologist, 5 no. 1, (March 1978): 3-20

Adler, Jonathan, "Epistemological Problems of Testimony," edited by Edward. Zalta, Stanford Encyclopedia of Philosophy, last modified April 17, 2017, https://plato.stanford.edu/entries/testimony-episprob/\#NatTesEpiVul

Aharoni, Eyal, Sinnott-Armstrong, Walter, and Kiehl, Kent, "Can Psychopathic Offenders Discern Moral Wrongs? A New Look at the Moral/Conventional Distinction", Journal of Abnormal Psychology, 121 no 2 (2012): 484-497

American Law Institute. "Model Penal Code" (Washington, 1962.

American Psychiatric Association, Antisocial Personality Disorder DSM-5 301.7 (F60.2) Diagnostic and Statistical Manual of Mental Disorders. (Washington, DC, 2013)

Beeby, Laura, "A Critique of Hermeneutical Injustice" Proceedings of the Aristotelian Society 111, (2011): 479-486

Blair, R.J.R “A Cognitive Developmental Approach to Morality: Investigating the Psychopath". Cognition, 57 no 1, (1995): 1-29

Blake, Emily, "Mandatory minimum sentence not unconstitutional for Hay River armed robber, says judge," CBC, March 27, 2018, https://www.cbc.ca/news/canada/north/mandatory-minimumsentence-robbery-firearm-1.4594867

Bloom, Paul “Empathy and its Discontents” Trends in Cognitive Science 21, no. 1 (2017): 24-31

Blonigen, Daniel, Hicks, Brian, Krueger, Robert, Patrick, Christopher, and Iacono, William, "Psychopathic Personality Traits: Heritability and Genetic Overlap with Internalizing and Externalizing Psychopathology." Psychological Medicine, 35 no 5, (2005): 637-648.

Book, Angela, Methot-Jones, Tabitha, Blais, Julie, Hosker-Field, Ashley, Volk, Anthony, Visser, Beth A., Gauthier, Nathalie, Holden, Ronald R., and D'Agata, Madeleine T. "Psychopathic Traits and the Cheater-Hawk Hypothesis" Journal of Interpersonal Violence, 34 no. 15 (2016): 3229-3251

Brandenburg, Daphne, “The Nurturing Stance: Making Sense of Responsibility without Blame”, Pacific Philosophical Quarterly, 99 no. 1 (2017): 5-22

Carel, Havi, and Kidd, Ian James, "Epistemic Injustice in Healthcare: a Philosophial Analysis" Medicine, Healthcare and Philosophy, 17, no.4 (2014): 529-540

Choi, Charles, "Brain tumour causes uncontrollable paedophilia," News Scientist, October 21, 2002. https://www.newscientist.com/article/dn2943-brain-tumour-causes-uncontrollablepaedophilia/

Cleckley, Hervey The Mask of Sanity; an Attempt to Reinterpret the so-Called Psychopathic Personality (St. Louis: The C.V. Mosby Company, 1941) 
Conn, Courtney, Warden, Rebecca, Stuewig, Jeffrey, Kim, Elysha H., Harty, Laura, Hastings, Mark, and J. Tangney, June P., "Borderline Personality Disorder Among Jail Inmates: How Common and How Distinct?" Corrections Compendium, 35 no. 4 (2010): 6-13

Cooke, David and Michie, Christine "Refining the Construct of Psychopathy: Toward a Hierarchical Model." Psychological Assessment, 13 no. 2 (2003): 171-188

Cornell School of Law, Aggravating Factor," Legal Information Institute, Accessed July 31, 2019 https://www.law.cornell.edu/wex/aggravating_factor

Criminal Code, RSC 1985, c. C - 718

Dotson, Kristie, "Tracking epistemic violence, tracking patterns of silencing." Hypatia 26 no 2 (2011): 236-257

Edens, John, Davis, Karen, Smith, Krissie, and Guy, Laura, "No Sympathy for the Devil: Attributing Psychopathic Traits to Capital Murderers Also Predicts Support for Executing Them", Personality Disorders: Theory, Research, and Treatment, 1 no 2 (2005): 175-181

"Empathy," Definition of Empathy in English, Lexico, accessed August 3, 2019, https://www.lexico.com/en/definition/empathy.

Eshleman, Andrew, "Moral Responsibility", The Stanford Encyclopedia of Philosophy (Winter 2016 Edition), Edward N. Zalta (ed.), https://plato.stanford.edu/archives/win2016/entries/moralresponsibility

Fantl, Jeremy, "Knowledge How", The Stanford Encyclopedia of Philosophy (Fall 2017 Edition), Edward N. Zalta (ed.), https://plato.stanford.edu/archives/fall2017/entries/knowledge-how/

Fine, Cordelia and Kennett, Jeanette, "Mental impairment, Moral Understanding and Criminal Responsibility: Psychopathy and the Purposes of Punishment", International Journal of Law and Psychiatry, 27 (2004): 425-443

Fricker, Miranda, Epistemic Injustice: Power and the Ethics of Knowing Oxford: Oxford University Press, 2007)

Gillespie, Rosemary, "Childfree and Feminine: Understanding the Gender Identity of Voluntarily Childless Women." Gender and Society 17, no. 1 (2003): 122-136.

Gert, Bernard and Gert, Joshua, "The Definition of Morality", The Stanford Encyclopedia of Philosophy (Fall 2017 Edition), Edward N. Zalta (ed.), https://plato.stanford.edu/archives/fall2017/entries/morality-definition/

Glenn, Andrea, Kurzba, Robert, and Raine, Adrian. "Evolutionary Theory and Psychopathy" Aggression and Violent Behavior, 16 (2011): 371-380

Hare, Robert D., The Hare Psychopathy Checklist Revised (Hare PCL-R) (Toronto: Multi-Health Systems, Incorporated, 2003)

Hare, Robert D., "Psychopathy and Antisocial Personality Disorder: A Case of Diagnostic Confusion" Psychiatric Times, 13, no. 2 (1996); Robert D. Hare, "Psychopathy and the DSM-IV Criteria for Antisocial Personality Disorder", Journal of Abnormal Psychology, 100 no. 3 (1991): 391-398 
Hare, Robert D., Without Conscience: The Disturbing World of the Psychopaths Among Us (New York: The Guilford Press, 1993)

Hawley, Katherine, "Knowing How and Epistemic Injustice" in Knowing How: Essays on Knowledge, Mind and Action, edited by John Bengson and Marc A. Moffett, 283-299, New York: Oxford University Press, 2011

Hookway, Christopher, "Some Varieties of Epistemic Injustice: Reflections on Fricker”, Episteme, 7 no. 2 (2010): 151-163

Justia, Aggravating and Mitigating Factors", Criminal Law, Accessed July 24, 2019, https://www.justia.com/criminal/aggravating-mitigating-factors/

Kennett, Jeanette, and Matthews, Steve "Mental Time Travel, Agency and Responsibility" in Psychiatry as Cognitive Neuroscience: Philosophical Perspectives edited by Matthew Broome \& Lisa Bortolotti, 327-350, Oxford: Oxford University Press, 2009

Kyratsous, Michalis and Sanati, Abdi, "Epistemic injustice and responsibility in borderline personality disorder", Journal of Evaluation in Clinical Practice, 23 (2017) 974-980

Levy, Neil, "Psychopaths and Blame: The Argument from Content" Philosophical Psychology, 27 no. 3 (2014): 351-367

Levy, Neil "The responsibility of the Psychopath Revisited", Philosophy, Psychiatry \& Psychology, 14 no. 2 (2007): 129-138

Litton, Paul, "Responsibility Status of the Psychopath: On Moral Reasoning and Rational SelfGovernance" Rutgers Law Journal, 39, No. 349 (2008) 349-391

Maibom, Heidi, “The Bad, The Mad and The Psychopath", Neuroethics, 1 no 3 (2008): 167-184

Maibom, Heidi, "Moral Unreason: The Case of Psychopathy", Mind and Language, 20 no 2 (2005): $237-257$

Maibom, Heidi, "Psychopathy: Morally Incapacitated Persons," edited by Thomas Schramme \& Steven Edwards Handbook of the Philosophy of Medicine (Dordrecht: Springer.2017): 1109-1129

"Mandatory Sentences of Imprisonment in Common Law Jurisdictions: Some Representative Models" Canada's Justice System, Department of Justice, last modified June 3, 2019, https://www.justice.gc.ca/eng/rp-pr/csj-sjc/ccs-ajc/rr05_10/p2.html

"Maternity (and Paternity) Leave and Pay," Rights and Responsibilities, Striking Women, Accessed July 24, 2019, https://www.striking-women.org/module/workplace-issues-past-andpresent/maternity-and-paternity-leave-and-pay

Mason, Rebecca 'Two kinds of unknowing.' Hypatia 26 no. 2 (2011): 294-307

McKinnon, Rachel, “Epistemic Injustice”, The Philosophy Compass, 11 no 8 (2016): 437-446

Miller v. Alabama, 567 U.S. 460 (2012)

Millon, Theodore, Simonsen, Erik, and Birket-Smith, Morten, "Historical Conceptions of Psychopathy in the United States and Europe." In Psychopathy: Antisocial, Criminal, and Violent Behavior Eds. Theodore Millon, Erik Simonsen, Morten Birket-Smith and Roger D. Davis (New York: The Guilford Press, 1998): 3-31 
Morse, Stephen J., "Psychopaths and Criminal Responsibility" Neuroethics 1, no. 3, (2008): 205-212

Nadelhoffer, Thomas and Sinnott-Armstrong, Walter, "Is Psychopathy a Mental Disease?" In Neuroscience and Legal Responsibility, edited by Nicole A. Vincent (New York: Oxford University Press, 2013), 229-255

Nagin, Danielle S., Piquero, Alex R., Scott, Elizabeth S., and Steinberg, Laurence, "Public Preferences for Rehabilitation versus Incarceration of Juvenile Offenders: Evidence from a Contingent Valuation Survey", Criminology and Public Policy, 5 no. 4, (2006): 627-651

Ogloff, James R. P., Rachel E. Campbell, Rachel E., and Shepherd, Stephane M., "Disentangling Psychopathy from Antisocial Personality Disorder: An Australian Analysis”, Journal of Forensic Psychology Practice, 16 no. 3 (2016): 198-215

Patrick, Christopher, Bradley, Margaret, and Lang, Peter, "Emotion in the Criminal Psychopath: Startle Reflex Modulation", Journal of Abnormal Psychology, 102 no 1 (1993): 82-92

Polhaus Jr., Gaile, "Relational Knowing and Epistemic Injustice: Toward a Theory of Wilful Hermeneutical Ignorance." Hypatia 27 no 4 (2012): 715-735

"Pregnancy Discrimination," About EEOC, U.S. Equal Employment Opportunity Commission, Accessed July 24, 2019, https://www.eeoc.gov/eeoc/publications/fs-preg.cfm

Quintelier, Kantinka and Fessler, Daniel, "Confounds in Moral/Conventional Studies", Philosophical Explorations 18 no 1 (2014): 58-67

R. V. Suter, 2018 SCC 34, [2018] 2 S.C.R. 496

Shaw, Elizabeth "Psychopathy, Moral Understanding and Criminal Responsibility", European Journal of Current Legal Issues, 22 no 2 (2016): 1-25

Shoemaker, David, "Attributability, Answerability, and Accountability: Toward a Wider Theory of Moral Responsibility” Ethics, 121 no. 3 (2011): 602-632

Strawson, Peter F., "Freedom and Resentment," Proceedings of the British Academy, 48 (1962): 1-25 Reprinted in Fischer and Ravizza, 1993

Strimple, Earl 0. "A History of Prison Inmate-Animal Interaction Programs." American Behavioral Scientist 47, no. 1 (September 2003): 70-78.

Sturup, Joakim, Edens, John, Sörman, Karolina, Karlberg, Daniel, Fredriksson, Björn and Kristiansson, Marianne, "Field Reliability of the Psychopathy Checklist-Revised Among Life Sentenced Prisoners in Sweden" Law and Human Behaviour, 38 no 4 (2013): 1-10

Thomas Suddendorf, and Michael C. Corballis, "The Evolution of Foresight: What is Mental Time Travel and is it Unique to Humans?" Behavioral and Brain Sciences, 30, no 3, (2007) 299-313

"Sympathy," Definition of Sympathy in English, Lexico, accessed August 3, 2019, https://www.lexico.com/en/definition/sympathy.

Talbert, Matthew, "Blame and Responsiveness to Moral Reasons: Are Psychopaths Blameworthy?" Pacific Philosophic Quarterly, 89 no. 4 (2008): 516-535 
Tanasescu, Gabriel, "The Causal Link between Functional Disorder of the Orbitofrontal Cortex, Disorder of Moral Reasoning and Aggressive Sexual Behavior" Rais Journal for Social Sciences, 3 no. 1 (2019): 99-113

"The Characters of Theophrastus," Translated by R.C. Jebb accessed August 3, 2019, https://www.eudaemonist.com/biblion/characters/

The Review Board Systems in Canada: An Overview of Results from the Mentally Disordered Accused Data Collection Study, Canada's Justice System, Department of Justice, Last Modified January 7 2015, https://www.justice.gc.ca/eng/rp-pr/csj-sjc/jsp-sjp/rr06_1/p1.html

Vargas, Manuel and Nichols, Shaun, Psychopaths and Moral Knowledge, Philosophy, Psychiatry, \& Psychology, 14 no. 2 (2007): 157-162

Vierra, Andrew, "Psychopathy, Mental Time Travel and Legal Responsibility" Neuroethics, 9 (2016): $129-136$

Virginia Department of Behavioural Health and Developmental Science "The Insanity Defense and the NGRI finding" accessed July 31, 2019, http://www.dbhds.virginia.gov/library/forensics/ofo\%20\%20section\%201\%20all\%20sections.pdf

Whitlock, F.A "A Note on Moral Insanity and Psychopathic Disorders". Psychiatric Bulletin. 6 no.4 (April 1982): 57-59

Young, Brent, Conti, David, and Dean, Matthew, "Sneaker "Jack" Males Outcompete Dominant "Hooknose" Males under Sperm Competition in Chinook Salmon (Oncorhynchus Tshawytscha), Ecology and Evolution 3 no 15 (2013): 4987-4997

Zhong, Rocksheng, Baranoski, Madelon, Feigenson, Neal, Davidson, Larry, Buchanan, Alec, and Zonana, Howard V., "So You're Sorry? The Role of Remorse in Criminal Law", Journal of the American Academy of Psychiatry and the Law, 42, no. 1, (March 2014), 39-48 